\title{
molecules
}

ISSN 1420-3049

www.mdpi.com/journal/molecules

Review

\section{Supramolecular Complexation of Carbohydrates for the Bioavailability Enhancement of Poorly Soluble Drugs}

\section{Eunae Cho ${ }^{1}$ and Seunho Jung ${ }^{1,2,3, *}$}

1 Center for Biotechnology Research in UBITA (CBRU), Institute for Ubiquitous Information Technology and Applications (UBITA), Konkuk University, 120 Neungdong-ro, Gwangjin-gu, Seoul 05029, Korea; E-Mail: echo@konkuk.ac.kr

2 Microbial Carbohydrate Resource Bank (MBRC), Konkuk University, 120 Neungdong-ro, Gwangjin-gu, Seoul 05029, Korea

3 Department of Bioscience and Biotechnology, Konkuk University, 120 Neungdong-ro, Gwangjin-gu, Seoul 05029, Korea

* Author to whom correspondence should be addressed; E-Mail: shjung@konkuk.ac.kr; Tel.: +82-2450-3520; Fax: +82-2452-3611.

Academic Editor: Holger Grohganz

Received: 15 September 2015 / Accepted: 22 October 2015 / Published: 27 October 2015

\begin{abstract}
In this review, a comprehensive overview of advances in the supramolecular complexes of carbohydrates and poorly soluble drugs is presented. Through the complexation process, poorly soluble drugs could be efficiently delivered to their desired destinations. Carbohydrates, the most abundant biomolecules, have diverse physicochemical properties owing to their inherent three-dimensional structures, hydrogen bonding, and molecular recognition abilities. In this regard, oligosaccharides and their derivatives have been utilized for the bioavailability enhancement of hydrophobic drugs via increasing the solubility or stability. By extension, polysaccharides and their derivatives can form self-assembled architectures with poorly soluble drugs and have shown increased bioavailability in terms of the sustained or controlled drug release. These supramolecular systems using carbohydrate will be developed consistently in the field of pharmaceutical and medical application.
\end{abstract}

Keywords: poorly soluble drugs; carbohydrates; supramolecular complexation; bioavailability enhancement 


\section{Introduction}

Poorly soluble drugs belong to Biopharmaceutics Classification System (BCS) class II (low solubility/high permeability) and IV (low solubility/low permeability) materials [1]. The poor aqueous solubility of drugs has been a main obstacle in drug discovery and development, since it results in poor bioavailability at the active site [2]. With increasing molecular weight and $\log p$ values, the solubility of drugs decreases. Actually, $40 \%$ of drug candidates have been listed as practically insoluble $(<100 \mu \mathrm{g} / \mathrm{mL})$, whereas only $8 \%$ of new drug candidates have shown both high solubility and permeability $[1,3]$. To enhance the bioavailability of insoluble drugs, various techniques, including use of co-solvents, micronization, salt formation, and supramolecular complexation have been reported [4,5]. In the case of most non-intravenous administrations, the bioavailability is much less than $100 \%$, because all drugs may not be adsorbed and metabolized before the delivery at the target site. This review aims to shed light on the supramolecular complexation of drugs with carbohydrates for bioavailability enhancement with flexibility and simplicity in the design and resulting in a considerable increase in the solubility and dissolution of drugs.

Supramolecular chemistry is defined as "chemistry beyond the molecule" and its importance has been established by the award of the 1987 Nobel Prize in chemistry [6]. For biochemical interactions, the classical lock-and-key model has been changed and extended. Biomolecular architectures such as proteins, DNA, and bio-membranes are rather formed by supramolecular interactions, and they regulate the biological processes [7,8]. A lot of bioinspired materials have also been developed using supramolecular chemistry [9]. Self-assembly, molecular recognition, metal coordination, folding, and host-guest chemistry are the sophisticated concepts of supramolecular chemistry $[10,11]$. They are mainly composed of various noncovalent interactions including hydrogen bonding, dipole-dipole interactions, van der Waals forces, pi-pi interactions, and electrostatic interactions between molecules [12].

Hydrogen bonding plays crucial roles in biological molecular recognition together with other noncovalent interactions [13]. Carbohydrates $\left(\mathrm{C}_{\mathrm{n}} \mathrm{H}_{2 \mathrm{n}} \mathrm{O}_{\mathrm{n}}\right)$, the key molecules in Nature, are polyhydroxyaldoses or ketoses, which are the possible hydrogen bonding donors and/or acceptors. They are also coated onto all the cells and involved in various types of supramolecular interactions. Through cooperative hydrogen bonding, carbohydrate recognition mediates cell-cell interactions, pathogenesis, and immune responses [14,15]. To the supramolecular chemist, the recognition ability of carbohydrates can be useful for the biomedical application such as drug delivery and development. Therefore, carbohydrate-based drug development has grown rapidly as a promising and exciting research field. In particular, the supramolecular association of carbohydrates with drugs could enhance the bioavailability of poorly soluble drugs. The strategies are varied, depending on the carbohydrate types such as monosaccharides, oligosaccharides, and polysaccharides.

\section{Monosaccharides}

\subsection{Prodrug System}

Using monosaccharides, drug-monosaccharide conjugates can be used as a type of prodrug. An anticancer drug, dodetaxel, was conjugated with the glucose moiety, resulting in 52-fold increase in its solubility compared to the original drug [16]. Glucuronide prodrugs of doxorubicin and glycosyllonidamine have been reported [17-19]. Several antitumor agents such as bleomycin, anthracycline, and mithramycin also have a glycosidic moiety in their intrinsic structures. Their water solubility can be increased by the 
modulation of their hydrophilicity, and the glycosylated drugs can take advantage of the recognition by glucose transporters [20]. As another example, when a neurotransmitter for antiparkinsonian agents is glycosylated, the glycoconjugate could be delivered into the central nervous system across the blood brain barrier [21,22]. Some peptide drugs have been glycosylated, and their physicochemical and pharmacological properties also changed [23,24]. They undergo enzymatic hydrolysis in plasma, and the free drugs can be released and become active for in vivo investigation.

\subsection{Glycosylated Carrier}

For drug delivery, various carriers such as liposomes, micelles, dendrimers, micro/nanoparticles, and micro/nanocapsules are available [25-27]. The use of monosaccharides offers the characteristic effects for the advanced carrier system of poorly soluble drugs [28]. Since carbohydrate binding proteins are present on different cell surfaces, glycosylated carriers can be designed for targeted delivery [29]. Furthermore, galactose-, fucose-, and mannose-conjugated carriers show bioadhesive properties, stability/solubility enhancement, and reduced immunogenicity/toxicity [30-32]. In terms of solubility of poorly soluble drugs, the limited effect of monosaccharides can be overcome by the use of oligosaccharides.

\section{Oligosaccharides}

\subsection{Binary Systems}

\subsubsection{Cyclic Oligosaccharides and the Derivatives}

Cyclodextrin (CD): In 1896, the use of CD glucosyltransferase (CGTase) allowed a practical production of CD from starch. CDs are cyclic $\alpha-D-1,4$ glucans, most commonly composed of 6,7 and 8 glucosidic units called $\alpha-, \beta$-, and $\gamma$-CD, respectively (Figure 1a). The macrocycles can maintain a conformationally constrained structure compared to linear structures. The respective cavity diameters of $\alpha-, \beta-$, and $\gamma$-CDs are in the ranges $4.7-5.3,6.0-6.5$, and $7.5-8.3 \AA$, and the height of the torus is $7.9 \AA$ in all types [33,34]. In 1911, the first noncovalent host-guest inclusion complexation of CD and other molecules was reported, and the first drug/CD patent was disclosed in 1953 [35,36]. With the characteristic cone or torus shape, various drugs containing ibuprofen, itraconazole, diclofenac, or atenolol have been incorporated into the cavity of $\beta-C D$ even now, with a significant enhancement in the stability or solubility [37-40]. This is reasonable because $\mathrm{CD}$ can prevent crystallization, increase the dissolution of hydrophobic drugs, and protect the degradation of labile drugs by shielding guests with the hydrophobic cavity and the external layer of hydrophilic carbohydrates. They may also decrease the drug toxicity by making the drug more effective at lower doses. Furthermore, the native CD has Generally Regarded as Safe (GRAS) status in the United States and is found in many pharmaceutical and biomedical products.

CD derivatives: $\beta$-CD is generally used owing to its easy availability and appropriate size, however its solubility in water is relatively low $(1.8 \%)$ because of the intramolecular hydrogen bonding and strong order on the surrounding water [41]. To improve the complexation ability and aqueous solubility, CD derivatives have been synthesized (Figure 1b), and the aqueous solubilities of hydroxypropyl (HP-), methyl (M-), and sulfobutylether (SBE-) $\beta$-CDs are $>60 \%, 50 \%$, and $50 \%$, respectively [34]. Using HP- $\beta-C D$, nonpolar drugs such as itraconazole, indomethacin, hydrocortisone, cisapride, and mitomycin 
were marketed in the complex form in Europe and the United States [42,43]. HP- $\beta-C D$ is also much more toxicologically benign than the natural $\beta-\mathrm{CD}$ [44]. In the case of $\mathrm{M}-\beta-\mathrm{CD}$ or SBE- $\beta-\mathrm{CD}$ derivatives, the antibacterial chloramphenicol or the antifungal voriconazole have been introduced as complex solution formulations. However, because $\mathrm{M}-\beta-\mathrm{CD}$ has hemolytic activity based on the complexation with cholesterol from membranes, its oral administration is limited [45]. Using ionic interactions, carboxymethyl- and (2-hydroxy-3-(trimethylammonio)propyl) $\beta$-CDs have been investigated for their solubilizing effect with oppositely charged drugs [46]. Finally, dimeric or oligomeric $\beta$-CD have attracted much attention as versatile receptors for molecular recognition [47]. Two or more hydrophobic complexation sites can enhance the stability, selectivity, and flexibility towards various nonpolar drugs. For example, the complexes of titanocene or paclitaxel with $\mathrm{CD}$ dimer are fairly soluble in water (Figure 1c), and the bioavailability is dramatically improved compared to the original drug $[48,49]$.

(a)

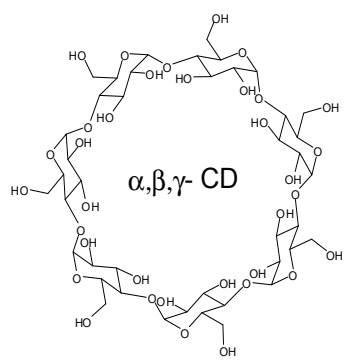

(d)

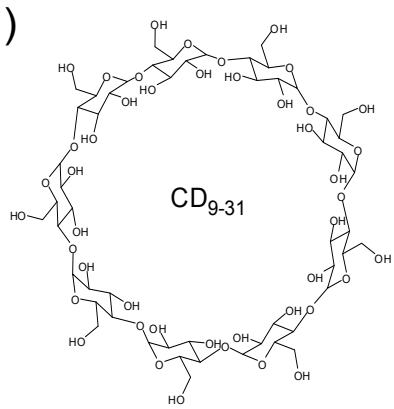

(b)

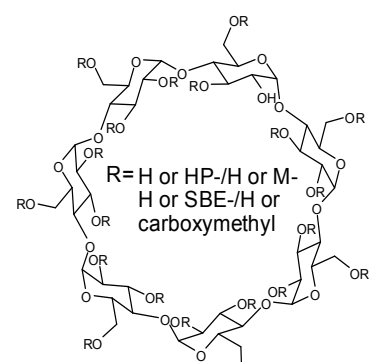

(e)

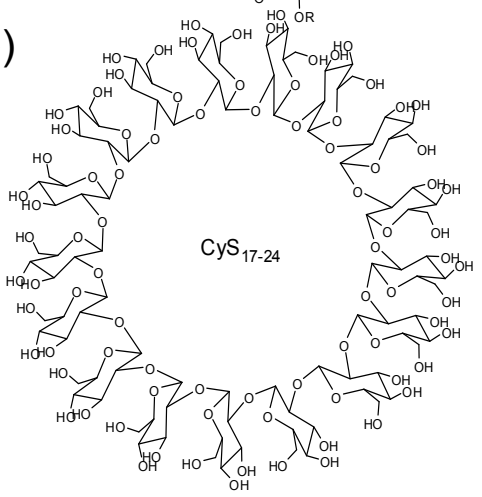

(c)

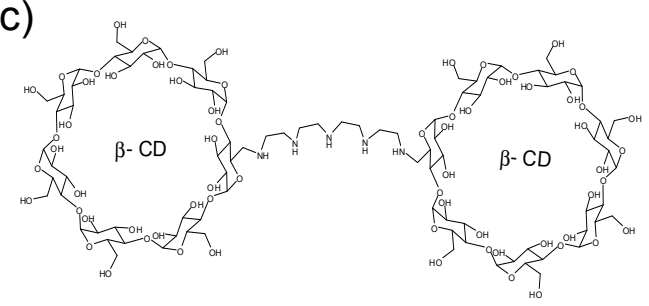

(f)

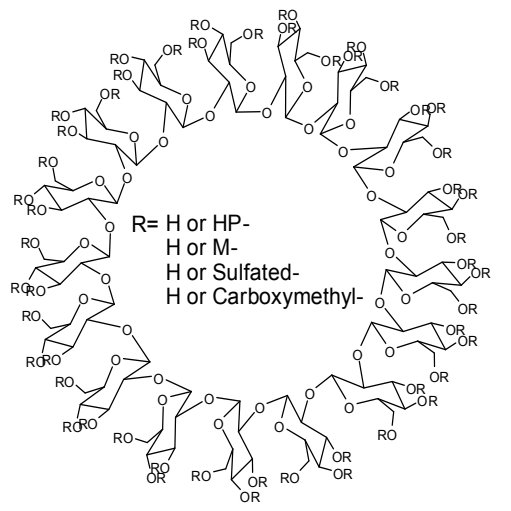

(g)

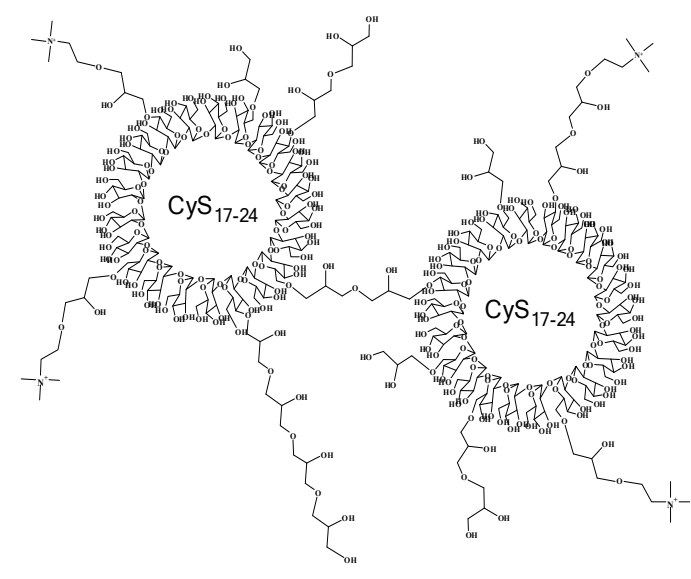

(h)

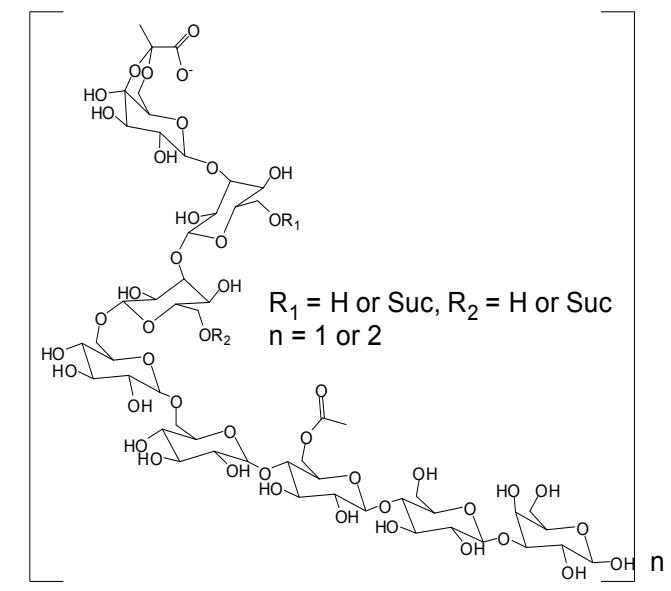

Figure 1. Oligosaccharide hosts in binary system. (a) CD; (b) CD derivatives; (c) CD dimer; (d) Large CD; (e) CyS; (f) CyS derivatives; (g) Cys dimer; and (h) Linear oligosaccharides.

Large CDs: The large CD comprising more than eight glucose units was isolated from the reaction mixture of CGTase and starch in 1957 by French and co-workers (Figure 1d) [50]. The CDs containing nine to 13 
glucoses are sequentially called as $\delta-, \varepsilon-, \zeta-, \eta-$, and $\theta-\mathrm{CD} . \delta-\mathrm{CD}(\mathrm{CD} 9)$ is found to be not a doughnut-shaped but rather elliptic boat-shaped, and has shown a solubilization effect for large guests such as digitoxin and spironolactone [51,52]. $\mathrm{CD}_{10}, \mathrm{CD}_{14}$ and $\mathrm{CD}_{26}$ also display distorted structures containing double band-flip motifs owing to their inherent flexibility [53,54]. Although the complex itself is less stable than the rigid $\alpha-, \beta$-, and $\gamma$-CDs, the flexible complex may be better for the effective release of drugs [55]. Furthermore, a variety of cavity sizes can be useful for special guests not geometrically suitable for $\alpha$-, $\beta$-, and $\gamma$-CDs.

Cyclosophoraoses (CyS) and the derivatives: CyS isolated from Rhizobium species are cyclic $\beta-1,2$ glucans containing 17 and 40 glucose residues (Figure 1e). In 1984, CyS 17 were found to exhibit the complexation ability with hydrophobic guests including indomethacin, propericiazine, reserpine, and steroids [56]. The cavity was considered to be able to accommodate three-dimensionally extended guest molecules, and the diameter and depth of the cavities were estimated as 9 and $15 \AA$ according to the CPK models. Besides, $\mathrm{CyS}_{17-24}$ efficiently complexed with paclitaxel, indomethacin, or luteolin [57-59]. The molecules are shaped such as a distorted and flexible ring, and the possibility of a different molecular mechanism for the complexation from the typical inclusion complexation by CD was suggested [60,61]. They could also be substituted by various functional groups including carboxymethyl, hydroxypropyl, sulfated, or methyl groups (Figure 1f) [62-65]. CyS oligomers were also designed (Figure 1g), and the cooperative complexation enhanced solubility and bioavailability of fisetin [66]. Because the functionalized $\mathrm{CyS}_{17-24}$ provide the additional space and property for guests, they are expected to behave as promising solubilizers for poorly soluble drugs.

\subsubsection{Linear Oligosaccharides}

Further, host-guest complexation was not found to be the exclusive property of cyclic structures. In 1989, it was demonstrated that cell-cell recognition is initiated by direct oligosaccharide-oligosaccharide interactions, indicating hydrophobic effects are responsible for the interaction [67]. In carbohydrate-protein interactions, stacking and non-polar interactions between sugar and tryptophan or phenylalanine residues of proteins were also observed, together with hydrogen bonds or metal coordination [68]. From this point of view, the hydrophobic character of linear carbohydrates was investigated with fluorescence probes, and the host-guest complexation might involve an induced-fit type adjustment [69]. Non-cyclic hexadecasaccharide has been reported as an effective complexing agent for pyrimethamine, haloperidol, or isoflavonoids (Figure 1h) [70-72]. In fact, the solubility of the antimalarial drug pyrimethamine and antipsychotic medication haloperidol was increased 42- and 87-fold in water by complexing with succinoglycan dimer D3 [70,71]. Even in octasaccharides, a solubility enhancement of pindolol was described, and their cytotoxic effect was low enough to warrant further study [73]. Recently, an acyclic cucurbit $[n]$ uril molecular container has also been reported to overcome potential limitations such as the structural rigidity and slow dissociation kinetics of macrocyclic cucurbit $[n]$ urils [74]. Acyclic oligosaccharides would be flexible hosts to recognize a broad range of poorly soluble drugs and provide high dissociation kinetics. 


\subsubsection{Preparation of Inclusion Complexes}

To overcome the practical problems, including long processing time, the use of excessive solvent, and multistep synthesis, practical preparation methods have been developed as follows. The preparation can be optimized depending on the substrates.

Kneading [75]: In this method, carbohydrate hosts were placed in a mortar and wetted with little amount of water or hydro-alcoholic solution. Subsequently, the drug was added to the host paste, and the mixture was kneaded for a specified time. Finally, the kneaded sample was dried.

Freeze-drying [76,77]: Drugs and carbohydrate hosts were dissolved in water to achieve equilibrium, and the solutions were frozen by immersion in liquid nitrogen, and the frozen solutions were lyophilized.

Spray-drying [78]: Aqueous solutions of carbohydrate hosts and alcoholic solution of drugs are mixed to produce a clear solution. The solution is then spray-dried using a spray dryer.

\subsubsection{Analysis of Inclusion Complex}

1. UV-Vis spectroscopy-Measurement of drug solubility enhancement by complexation.

2. Nuclear Magnetic Resonance (NMR) spectroscopy $-{ }^{1} \mathrm{H}-\mathrm{NMR}$ is a suitable method for the evaluation of noncovalent interactions at the molecular level [79]. To elucidate the intermolecular interaction of inclusion complexes, two-dimensional NMR spectroscopy (Nuclear Overhauser enhancement spectroscopy (NOESY) or Rotating frame nuclear Overhauser effect spectroscopy (ROESY)) has also been frequently used, because two protons located within $5 \AA$ induce an NOE crosspeak [80].

3. Thermogravimetric Analysis (TGA)/Differential Scanning Calorimetry (DSC)—TGA curves describe the weight losses of pure components and the complexes. DSC is performed to characterize the solid-state interactions for the inclusion complexes as compared to the melting points [81].

4. Fourier Transform Infrared (FTIR) spectroscopy - The analysis of the vibrational changes upon the inclusion of drugs with a host.

5. X-ray Powder Diffractometry (XRPD) - The powder diffraction patterns of drugs and complex are compared. In principle, drugs displayed sharp peaks, which are the characteristics of an organic molecule with crystallinity, and the complex shows different patterns with crystalline drugs.

6. Scanning Electron Microscopy (SEM) - The surface morphology of the pure and complexed form is investigated. The morphological changes are frequently analyzed to evaluate the interaction between drugs and host [82,83].

7. Electrospray mass spectrometry (ESI-MS)-Determination of molecular association of noncovalent bonding.

8. Computational method (Molecular modeling) - The appropriate binding mode of complex between host and drug can be derived from molecular docking simulations [84].

\subsubsection{Phase Solubility Studies}

The complexation between drugs and carbohydrates is caused by forming dynamic non-covalent bonds, which increases the aqueous solubility of drugs. In phase-solubility diagram (Figure 2), the solubility 
enhancement of drugs is assessed as a function of host concentration [85]. Based on the shape of the plot, the diagram is classified as $\mathrm{AP}_{\mathrm{P}} \mathrm{A}_{\mathrm{L}}, \mathrm{A}_{\mathrm{N}}, \mathrm{Bs}_{\mathrm{s}}$, or $\mathrm{B}_{\mathrm{i}}[42]$.

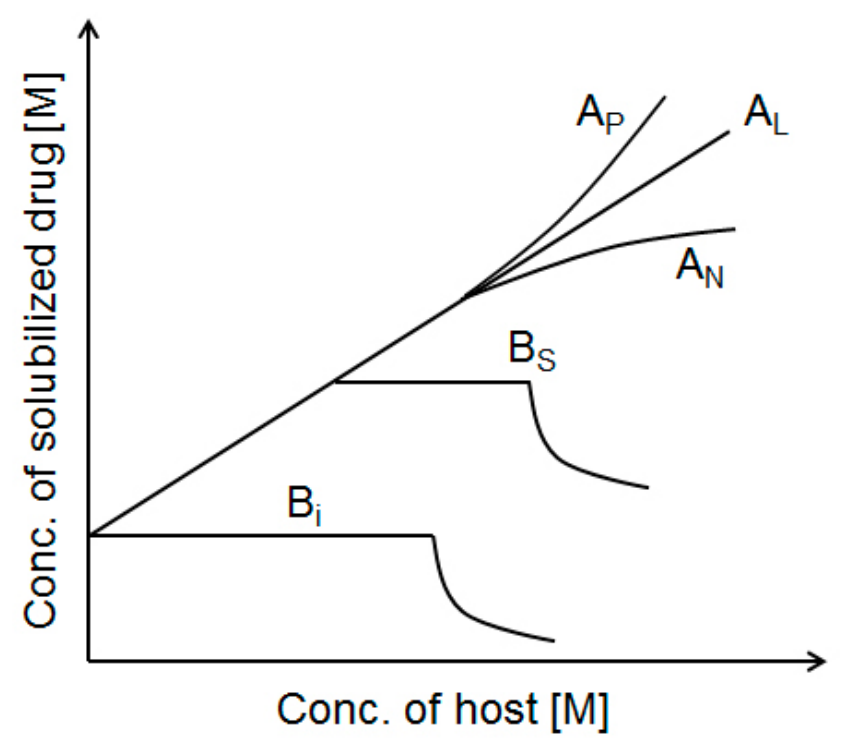

Figure 2. Phase solubility diagram.

A type profile: In this profile, the apparent solubility of drugs increases as a function of host concentration. The AL graph indicates a linear increase in solubility, whereas Ap and AN type graphs indicate a positive and negative deviation from linearity, respectively. Although $A_{N}$ systems are not easy to interpret, AP type suggests the formation of a higher-order complex with respect to the host. In AL type, a plot of drug concentration $\left(\mathrm{D}_{\mathrm{t}}\right) v s$. host concentration $\left(\mathrm{H}_{\mathrm{t}}\right)$ for the formation of $\mathrm{D}_{\mathrm{m}}-\mathrm{H}$ complex gives a linear line with the intercept and the slope is defined as:

$$
\text { slope }=\mathrm{mKS}_{0}^{\mathrm{m}} /\left(1+\mathrm{KS}_{0}^{\mathrm{m}}\right)
$$

where, if $\mathrm{m}$ is known, the $\mathrm{K}$ value can be calculated from the slope and intercept ( $\mathrm{S}_{0}$, the intrinsic solubility of the drug in water).

If the complex has a 1:1 drug:host ratio, the complexation is an equilibrium governed by an equilibrium constant $\left(\mathrm{K}_{1: 1}\right)$ calculated based on the linear phase-solubility profiles ( $\mathrm{A}_{L}$ type) using the following equation:

$$
\mathrm{K}_{1: 1}\left(\mathrm{M}^{-1}\right)=\text { slope } / \mathrm{S}_{0}(1-\text { slope })
$$

In this case, the slope is always less than unity [86]:

In the case of 2:1 drug:host complexation, the slope of the $A_{L}$ type diagram is less than two, and the association constant $\left(\mathrm{K}_{2: 1}\right)$ is determined by the following equation [87]:

$$
\mathrm{K}_{2: 1}\left(\mathrm{M}^{-1}\right)=\text { slope } / \mathrm{S}_{0}^{2}(2-\text { slope })
$$

B type profile: When the system forms complexes with limited solubility, the diagram is B type, which is usually observed with $\beta$-CD. Bs type is derived from the initial soluble complex and insoluble complex at the maximum point. $\mathrm{B}_{\mathrm{i}}$ style indicates that the complex is too insoluble to increase the isotherm. 


\subsubsection{Drug Delivery and CD Elimination from the Drug/CD Complexes}

Complexation certainly involves the issue of the mechanism(s) of drug release. The answer is thought to be dissociation owing to dilution, protein binding, tissue uptake of drugs, competitive displacement of drugs from the complex, and host elimination [88,89]. These drug/host complexes may alter drug metabolism route, biodistribution, and tubular reabsorption, and thereby the bioavailability of drugs can be changed. In particular, myricetin [90], isotretinoin [91], benznidazole [92], and etodolac exhibit 9.4-, 4.7-, 3.6-, and 2.5-fold increases in bioavailability upon addition of drug/CD derivative complexes for their oral administration [93]. As well as, the CDs are ultimately digested by bacteria in the gastrointestinal tract or colon to monosaccharides or gases including carbon dioxide, hydrogen, and methane [94].

\subsection{Ternary Systems}

Ternary systems have been designed to improve the shortcomings of the above binary systems. In general, the main property of carbohydrate hosts is the modification of the physicochemical and biological characteristics of poorly soluble drugs by complex formation. Using another factor, ternary complexes could be more efficient for the solubility and bioavailability of drugs with the use of a small amount of carbohydrates. As modifiers, organic acids such as ascorbic acids, citric acids, and tartaric acids are used together with $\beta-\mathrm{CD}$, and they can modulate the $\mathrm{pH}$ under aqueous conditions $[95,96]$. Accordingly, the solubility, stability, and phase solubility types are simultaneously affected. Besides, arginine, co-solvent, and a suitable water-soluble polymer also provided a synergistic effect for improving drug solubility in the presence of CD [97-99]. By adding the third auxiliary substance, lecithin, the solubility, dissolution, and stability of drugs were better than that those of the original drugs and binary systems [100]. Based on the amphiphilic properties of lecithin, the hydrophobic interactions with drugs, hydrogen bonding with HP- $\beta-\mathrm{CD}$, and the cooperative advantage is greater than the simple statistical contributions of individual components.

\subsection{Multinary Systems}

\subsubsection{Amphiphiles}

CD can even be conjugated to lipid molecules, and the amphiphile forms a micellar or vesicular system via self-assembly [101-104]. The resulting structure provides a higher drug loading, stable colloidal system, and controlled drug release. The first amphiphilic CDs were synthesized by Kawabata et al., in 1986, and the alkylsulfinyl $\beta$-CD showed interesting molecular assembly properties [105]. Recently, anthraquinoyl-, hexadecyl-, sulfated hexanoyl-modified $\beta$-CDs were developed for the delivery of anticancer (paclitaxel, docetaxel), and antiviral (acyclovir) drugs [106-108]. Supramolecular amphiphiles are of significant interest as hybrid materials with inclusion capacity and nanoparticulate properties [101].

\subsubsection{Pendent Polymers}

At the same time, CD-containing polymers have been explored for novel drug delivery platforms and are more suitable in medication for parenteral adminstration than the natural $\beta-C D[109,110]$. The systems consist of the polymeric, assembled network, and host-guest complexation, allowing the effective loading 
and controlled release of drugs. Depending on the crosslinkers, soluble or insoluble $\beta$-CD polymers are obtained. Hyper-crosslinked CDs were first called nanosponges in 1998 [111], and insoluble polymers have been used as excipients in preparing tablets, suspensions, and capsules for drug carriers with soluble CD polymers $[112,113]$. For doxorubicin delivery to treat some leukemias and cancers, quaternary ammonium crosslinked $\beta$-CD and $\beta$-CD-centered amphiphilic polymers were achieved $[114,115]$. The three-dimensional architecture of CD pendent polymers usually forms hydrogels or nanoparticles, which are potentially superior in the biomedical and pharmaceutical fields.

\section{Polysaccharides}

Polysaccharides are polymeric carbohydrate molecules composed of monosaccharide units bound together by glycosidic linkages. They vary depending on their sources and structural units, and are easily available, inexpensive, eco-friendly, and biocompatible materials. Based on their primary sequence, they can adopt certain shapes (secondary structures like ribbons and helices) and the ordered specific structure (tertiary structures of multiple ribbons and helices) formed via energetically favorable interactions [116]. Sometimes, quaternary structures have shown higher levels of organization. Using these supramolecular polysaccharides, multi-dimensional carrying systems were prepared to control the drug release in a desirable manner.

\subsection{Polysaccharide Drug Conjugates}

In 1975, the concept of polymer-drug conjugates was introduced for the first time for the delivery of hydrophobic drugs to their sites of action [117]. The conjugates alter the biodistribution and circulation time of the original drugs. So far, hyaluronic acid [118,119], dextran [120], chitosan [121], heparin [122], alginate [123], pullulan [124], arabinogalactan [125,126], and starch have all been developed as drug conjugation platforms [127]. Hyaluronic acid is an anionic polysaccharide containing alternating disaccharide units of D-glucuronic acid and $N$-acetyl-D-glucosamine linked by $\beta-1,4$ glycosidic linkages. In the structure, the hydroxyl and carboxylic acid groups provide the appropriate sites for the conjugate. Because it has a strong affinity for the cancer cell marker, CD44, the selective adsorption is an additional advantage for the anticancer bioavailability [128]. Dextran is a glucan with mostly $\alpha-1,6$ glycosidic linkages and has been approved as a plasma expander [129]. Chitosan is a biopolymer of $\beta-(1-4)-$ linked D-glucosamine and $\mathrm{N}$-acetyl-D-glucosamine, and the reactive amine group is important for chemical modification. The muco-adhesive property and the insolubility at $\mathrm{pH} 7.4$ are considered for the development into advanced materials. Heparin is a highly sulfated glycosaminoglycan and has been used as the anticoagulant. Alginate is a linear copolymer of $\beta$-1,4-mannuronate and $\alpha$-guluronate, and its gel-forming ability via calcium binding is a characteristic property. Pullulan is a neutral polysaccharide composed of maltotrioses linked by $\alpha-1,4$ and $\alpha-1,6$ bond types, and starch consists of helical amylose and branched amylopectin. Arabionogalactan is a heteropolymer consisting of arabinose and galactose. Among these, hyaluronic acid, carboxymethyl dextran, and oxidized dextran conjugates have entered clinical trials [118,130-132], showing improved adverse reaction profiles, enhanced therapeutic efficacy, and target-oriented properties. 


\subsection{Supramolecular Architectures for Polysaccharide Drug Carriers}

Polysaccharides provide supramolecular architectures derived from cooperative intra- and interchain association by hydrogen bonding, dipole and ionic interactions, and solvation (Figure 3). Supramolecular structures have distinct structural characteristics and functions that are not shown in monosaccharide units. Furthermore, their reactive groups (hydroxyl, amino, and carboxylic acid) can be easily modified, and various polysaccharide derivatives have been synthesized as novel supramolecular architectures. The driving forces for the three-dimensional structures are classified as noncovalent and covalent methods (Table 1). Supramolecules can provide the high encapsulation efficiency and cell internalization, decrease side effects, and protect the liable drugs via supramolecular complexation. As a result, they are designed for controlled drug release to maintain a constant drug concentration for the desired time with minimum side effects.

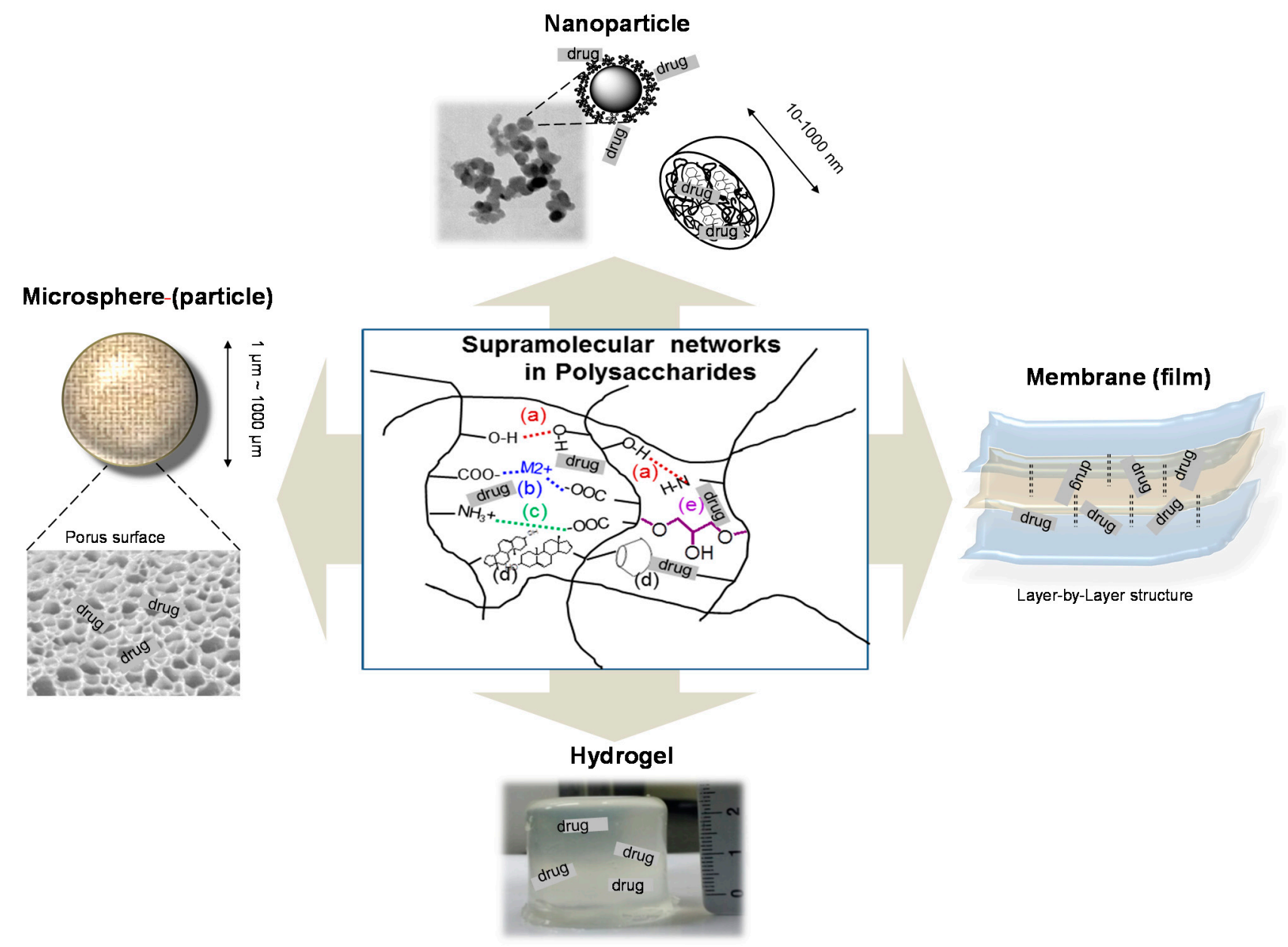

Figure 3. Polysaccharide-based advanced materials and supramolecular architectures for biomedical applications. The supramolecular architecture is formed by noncovalent methods such as hydrogen bonding (a); metal coordination (b); ionic interaction (c); hydrophobic interaction (d); and covalent methods using cross-linkers (e). 
Table 1. Polysaccharide-based carriers for the bioavailability enhancement of poorly soluble drugs.

\begin{tabular}{|c|c|c|c|c|c|}
\hline \multicolumn{2}{|c|}{ Supramolecular Forces } & \multirow[t]{2}{*}{ Used Polysaccharides } & \multirow[t]{2}{*}{ Architecture Types } & \multirow{2}{*}{$\begin{array}{c}\text { Drugs } \\
\text { Ondansetron }\end{array}$} & \multirow[t]{2}{*}{ References } \\
\hline \multirow{21}{*}{$\begin{array}{l}\text { Non-covalent } \\
\text { bond }\end{array}$} & \multirow{4}{*}{$\begin{array}{l}\text { Hydrogen } \\
\text { bond }\end{array}$} & & & & \\
\hline & & Hydrolyzed xyloglucan & Hydrogel & Indomethacin & {$[133-136]$} \\
\hline & & & & Mytomycin C & \\
\hline & & Hydroxypropyl Methylcellulose & Hydrogel & Indomethacin & [137] \\
\hline & \multirow{3}{*}{$\begin{array}{c}\text { Metal } \\
\text { coordination }\end{array}$} & Alginate-calcium ion & Nanoparticle & $\begin{array}{l}\text { Rifampicin, } \\
\text { Doxorubicin }\end{array}$ & {$[138,139]$} \\
\hline & & $N$-succinyl chitosan-alginate & Hydrogel & Nifedipine & [140] \\
\hline & & Alginate-calcium carbonate & Hydrogel & Ibuprofen & [141] \\
\hline & \multirow{7}{*}{$\begin{array}{c}\text { Ionic } \\
\text { interaction }\end{array}$} & Chitosan-tripolyphosphate & Nanoparticle & Ciprofloxacin & [142] \\
\hline & & Chitosan-tripolyphosphate-hydroxypropylcyclodextrin & Nanoparticle & $\begin{array}{l}\text { Furosemide, } \\
\text { Triclosan }\end{array}$ & [143] \\
\hline & & Chitosan-tripolyphosphate-dextran sulfate & Microsphere & Ibuprofen & [144] \\
\hline & & Chitosan-dextran sulfate & Nanoparticle & Amphotericin B & [145] \\
\hline & & Chitosan-glycyrrhetic acid & Nanoparticle & Glycyrrhetic acid & [146] \\
\hline & & Chitosan- $\beta$-glycerophosphate & Hydrogel & Paclitaxel & [147] \\
\hline & & Carrageenan Dextran sulfate & Nanosphere & Ciprofloxacin & [148] \\
\hline & \multirow{7}{*}{$\begin{array}{l}\text { Hydrophobic } \\
\text { interaction }\end{array}$} & Ceramide modified hyaluronic acid & Nanoparticle & $\begin{array}{l}\text { Docetaxel, } \\
\text { Doxorubicin }\end{array}$ & {$[149,150]$} \\
\hline & & Deoxycholic acid modified hyaluronic acid & Nanoparticle & Paclitaxel & [151] \\
\hline & & Histidine modified hyaluronic acid & Nanoparticle & Doxorubicin & [152] \\
\hline & & Pullulan acetate & Nanoparticle & Silymarin & [153] \\
\hline & & Cholesterol modified chitosan & Nanoparticle & Epirubicin & [154] \\
\hline & & Deoxycholic acid-modified chitosan & Nanoparticle & $\begin{array}{l}\text { Adriamycin, } \\
\text { Doxorubicin }\end{array}$ & {$[155,156]$} \\
\hline & & $5 \beta$-cholanic acid modified chitosan & Nanoparticle & $\begin{array}{c}\text { Paclitaxel, } \\
\text { Camptothecin }\end{array}$ & {$[157,158]$} \\
\hline
\end{tabular}


Table 1. Cont.

\begin{tabular}{|c|c|c|c|c|c|}
\hline \multicolumn{2}{|c|}{ Supramolecular Forces } & Used Polysaccharides & Architecture Types & Drugs & References \\
\hline \multirow{5}{*}{$\begin{array}{c}\text { Non-covalent } \\
\text { bond }\end{array}$} & \multirow{5}{*}{$\begin{array}{l}\text { Hydrophobic } \\
\text { interaction }\end{array}$} & Stearic acid-g-chitosan & Nanosphere & Doxorubicin & {$[159,160]$} \\
\hline & & $\mathrm{N}$-acetyl histidine-conjugated glycol chitosan & Nanoparticle & Paclitaxel & {$[161]$} \\
\hline & & Cholic acid modified dextran & Nanosphere & Indomethacin & [162] \\
\hline & & CD polymer-dextran polymer & Nanogel & $\begin{array}{l}\text { Benzophenone, } \\
\text { Tamoxifen }\end{array}$ & [163] \\
\hline & & Acetylated chondroitin sulfate & Nanogel & Doxorubicin & [164] \\
\hline \multirow{12}{*}{$\begin{array}{l}\text { Covalent } \\
\text { bond }\end{array}$} & \multirow{12}{*}{$\begin{array}{l}\text { Cross-linker or } \\
\text { Copolymer }\end{array}$} & Chitosan (glutaraldehyde, sulphuric acid) & Microsphere & $\begin{array}{c}\text { Diclofenac, } \\
\text { Docetaxol Clozapine }\end{array}$ & {$[165-167]$} \\
\hline & & Polyacrylamide- $g$-chitosan copolymer & Microsphere & Nifedipine & [168] \\
\hline & & Chitosan-Pluronic copolymer & Nanoparticle & $\begin{array}{l}\text { Indometacin, } \\
\text { Doxorubicin }\end{array}$ & {$[169,170]$} \\
\hline & & Pullulan-g-poly(l-lactide) copolymers & Hydrogel & Doxorubicin & [171] \\
\hline & & Poly(dl-lactide-co-glycolide)-grafted pullulan & Nanosphere & Adriamycin & [172] \\
\hline & & Cellulose-graft-poly(1-lactide) copolymers & Nanosphere & Paclitaxel & [173] \\
\hline & & Dextran- $b$-poly(DL-lactide-coglycolide) copolymer & Nanosphere & $\begin{array}{l}\text { Doxorubicin, } \\
\text { Amphotericin B }\end{array}$ & {$[174,175]$} \\
\hline & & Poly[lactic-co-(glycolic acid)]-grafted hyaluronic acid copolymer & Nanoparticle & Doxorubicin & {$[176]$} \\
\hline & & Dextran- $b$-poly(e-caprolactone $)$ & Nanoparticle & Doxorubicin & [177] \\
\hline & & Chondroitin sulfate-Pluronic copolymer & Nanoparticle & Doxorubicin & [178] \\
\hline & & Starch (epichlorohydrin) & Microsphere & Ampicillin & [179] \\
\hline & & Hyaluronic acid (1,3-diaminopropane) & Hydrogel & Ibuprofen & {$[180]$} \\
\hline
\end{tabular}


Among non-covalent bonds, hydrogen bonding is basically involved to make the supramolecular association of polysaccharides. With the same $\beta-1,4$-D-glucan backbone, xyloglucan and cellulose have ribbon-like shapes, and the modified structures can form hydrogel structures based on non-covalent interactions [133-137]. Carboxyl $(-\mathrm{COOH})$ groups in alginate are able to interact with divalent metals, and the resulting structures have been used for isoniazid, doxorubicin, nifedipine, and ibuprofen delivery [138-141]. On the other hand, cationic chitosan has been reported to form ionic self-assemblies by Coulombic interaction with various anionic molecules. The ionic interaction produces self-assembled delivery systems with well-defined shapes and dimensions (nano/micro-particles, hydrogels and films, Table 1. The other factor can be hydrophobic interactions caused by various hydrophobically modified polysaccharides, where the hydrophobic groups range from acetyl groups to lipid molecules [149,153,154,159,164]. The hydrophobized carrier might effectively adsorb and deliver the target guest via supramolecular chemistry [181]. Cross-linkers such as glutaraldehyde [165], epichlorohydrin [179], and 1,3-diamino-propane [180] can produce irreversible supramolecular architectures, which are also prepared from co-polymer structures with polyacrylamide [168],

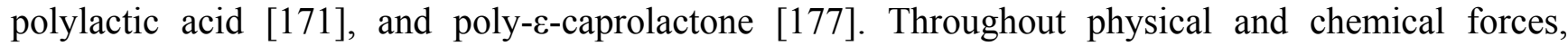
various carbohydrate architectures are observed such as microspheres, nanoparticles, films and hydrogels, which properties and advantages for the representative drug delivery system are discussed in the following subsections.

\subsubsection{Nano-Particles (Spheres)}

Nanoparticle entrapping drugs can penetrate cells and tissue gaps, and be delivered to the target organ with their nanosized dimensions. Particularly, polysaccharide-based nanoparticles control release profiles based on the biodegradability and stimuli ( $\mathrm{pH}$ or temperature)-responsive structural changes $[182,183]$. The major problems such as the cytotoxicity and degradation products of nanoparticles can also be solved based on their biocompatibility and biodegradability. The hydrophilic groups (hydroxyl, amino, and carboxyl groups) in polysaccharides provide bio-adhesive properties forming non-covalent bonds with biological tissues. Furthermore, some polysaccharides have recognition ability on specific cell types, allowing targeted delivery. These materials have the additional potential to combine diagnosis and therapy, and can be applied to nanomedicine. In this respect, polysaccharide (mostly dextran or chitosan)-coated magnetic nanoparticles have been attractive for drug delivery owing to their improved drug absorption, their prolonged blood residence time and target-specific delivery [184].

\subsubsection{Microspheres}

Polysaccharide-based microspheres can encapsulate many types of drugs, localize delivery of drug, and are easily administered through a syringe needle [185]. They have been commonly developed for treating many respiratory diseases, and the microsphere size is decisive for the release rate of drugs. The drug-polysaccharide supramolecular interactions and porosity may be other important factors. For pulmonary delivery, large particles may deposit in the respiratory tract before the target site, whereas small particles can aggregate before reaching the desired location. Depending on the polysaccharide species or molecular weight, the average particle sizes are varied by changing the solution viscosity [186]. The preparation methods for microsphere using polysaccharides are solvent extraction [187], spray-drying [188], emulsion-crosslinking $[166,179,189]$ and precipitation [190]. The conventional preparation methods 
have also been modified for property improvement. In the spray drying method, good sphericity and a narrow size distributions could be obtained, however the burst effect and fast drug release need to be solved. Using the w/o/w emulsion-spray drying method, famotidine was released for several hours with a sustained type from chitosan microsphere, and wetting agents could be utilized to increase the release rate [191].

\subsubsection{Membrane (Film)}

Membranes are mainly designed to control the release rate in transdermal delivery of drugs, and the applied materials can be used as tablet coatings, patches and wound dressings. The bio-adhesive and film-forming properties of polysaccharides are helpful for layer-by-layer type supramolecular structures [192]. Multilayers for the controlled delivery of drugs have advantages in terms of loading multiple components into interlayers and releasing the drugs sequentially layer-by-layer [193]. Although these films are regarded as more appropriate for hydrophilic drugs than hydrophobic ones [194,195], chitosan films were fabricated and used for local delivery of paclitaxel, and the biodegradation by lysozyme was used to control the drug release [196].

\subsubsection{Hydrogels}

Hydrogels are water-swollen and hydrophilic membranes with pseudo-plastic properties that absorb a high amount of water to maintain their shape. Water can penetrate into the interstitial spaces of the three-dimensional polysaccharide network, providing hydrogel-like artificial tissues [197]. The highly porous structure allows loading drugs into the gel matrix and subsequent drug release [198]. Furthermore, the physical properties are elastically active and have low interfacial tension in biological fluids. The drug release from hydrogels can be controlled by swelling, diffusion, and degradation [199]. As well as, the charge distribution and chemical modification in polysaccharide structures contributes to it along with the surface state or porosity. In many cases, since polysaccharides are resistant to degradation by gastric and intestinal bacteria and susceptible to digestion by colonic microbial flora, they have been studied as colon-specific drug delivery systems [200].

\section{Conclusions}

Supramolecular complexation of carbohydrates and poorly soluble drugs efficiently enhances the bioavailability of drugs. In the structure of carbohydrates, $-\mathrm{OH}$ and $-\mathrm{CH}$ groups provide the sites for hydrogen bonding and hydrophobic interactions, respectively. Furthermore, various modified carbohydrates can expand the scope of available drugs as well as the architecture. With monosaccharides, the targeted delivery of drugs was mainly considered. Typical binary complexes using linear and cyclic oligosaccharides were developed for poorly soluble drugs as two-dimensional systems, and the aqueous drug solubility was clearly enhanced by the binary system. In the intermediate version, tertiary complexes with another factor could reinforce the effect. Further, multiple complexes and polysaccharide-based supramolecules were recently studied as three-dimensional drug delivery systems. So far, various combinatorial hybrid materials of carbohydrates have been successfully developed for advanced drug carrier systems. Therefore, novel materials based on carbohydrates will be promising for advanced applications in the biomedical 
and pharmaceutical fields. Further, these works will improve micro/nano fabrication technology, bio-mimetics, and tissue engineering based on the supramolecular carbohydrate architecture.

\section{Acknowledgments}

This paper was supported by the KU Research Professor Program of Konkuk University. This research was also supported by grants from the National Research Foundation of Korea, funded by the Korean Government (NRF-2011-619-E0002), the Bio \& Medical Technology Development Program of the NRF funded by the Korean government, MSIP (2015M3A9B8031831), and Basic Science Research Program through the National Research Foundation of Korea (NRF) funded by the Ministry of Science, ICT \& Future Planning (NRF-2015R1C1A1A02037375).

\section{Author Contributions}

Author E. Cho prepared the first draft of the manuscript and S. Jung edited the final manuscript.

\section{Conflicts of Interest}

The authors declare no conflict of interest.

\section{References}

1. Takagi, T.; Ramachandran, C.; Bermejo, M.; Yamashita, S.; Yu, L.X.; Amidon, G.L. A provisional biopharmaceutical classification of the top 200 oral drug products in the United States, Great Britain, Spain, and Japan. Mol. Pharm. 2006, 3, 631-643.

2. Lipinski, C.A. Drug-like properties and the causes of poor solubility and poor permeability. J. Pharmacol. Toxicol. Methods 2000, 44, 235-249.

3. Okamoto, H. Novel Approaches for oral delivery of poorly soluble drugs. In Oral Delivery of Poorly Soluble Actives - From Drug Discovery to Marketed Products, Proceeding of Symposia on the Oral Delivery of Poorly Soluble Actives, Tokyo, Japan, 6 June 2003; Capsugel ${ }^{\circledR}$ Library: Morristown, NJ, USA.

4. Kawabata, Y.; Wada, K.; Nakatani, M.; Yamada, S.; Onoue, S. Formulation design for poorly water-soluble drugs based on biopharmaceutics classification system: Basic approaches and practical applications. Int. J. Pharm. 2011, 420, 1-10.

5. Jensen, K.T.; Blaabjerg, L.I.; Lenz, E.; Bohr, A.; Grohganz, H.; Kleinebudde, P.; Rades, T.; Löbmann, K. Preparation and characterization of spray-dried co-amorphous drug-amino acid salts. J. Pharm. Pharmacol. 2015, doi:10.1111/jphp.12458.

6. Lehn, J.-M. Supramolecular chemistry-Scope and perspectives: Molecules_-SupermoleculesMolecular devices. J. Incl. Phenom. 1988, 6, 351-396.

7. Timsit, Y.; Moras, D. DNA self-fitting: The double helix directs the geometry of its supramolecular assembly. EMBO J. 1994, 13, 2737-2746.

8. Uhlenheuer, D.A.; Petkau, K.; Brunsveld, L. Combining supramolecular chemistry with biology. Chem. Soc. Rev. 2010, 39, 2817-2826. 
9. Zhao, Y.; Sakai, F.; Su, L.; Liu, Y.; Wei, K.; Chen, G.; Jiang, M. Progressive macromolecular selfassembly: From biomimetic chemistry to bio-inspired materials. Adv. Mater. 2013, 25, 5215-5256.

10. Lehn, J.M. Supramolecular Chemistry; Wiley-VCH: Weinheim, Germany, 1995; Volume 1.

11. Lehn, J.M. Perspectives in supramolecular chemistry-From molecular recognition towards molecular information processing and self-organization. Angew. Chem. Int. Ed. Engl. 1990, 29, 1304-1319.

12. Schneider, H.J. Binding mechanisms in supramolecular complexes. Angew. Chem. Int. Ed. 2009, 48, 3924-3977.

13. Ariga, K.; Kunitake, T. Molecular recognition at air-water and related interfaces: Complementary hydrogen bonding and multisite interaction. Acc. Chem. Res. 1998, 31, 371-378.

14. Weis, W.I.; Drickamer, K. Structural basis of lectin-carbohydrate recognition. Annu. Rev. Biochem. 1996, 65, 441-473.

15. Carçabal, P.; Jockusch, R.A.; Hünig, I.; Snoek, L.C.; Kroemer, R.T.; Davis, B.G.; Gamblin, D.P.; Compagnon, I.; Oomens, J.; Simons, J.P. Hydrogen bonding and cooperativity in isolated and hydrated sugars: Mannose, galactose, glucose, and lactose. J. Am. Chem. Soc. 2005, 127, 11414-11425.

16. Shimoda, K.; Kubota, N. Chemo-enzymatic synthesis of ester-linked docetaxel-monosaccharide conjugates as water-soluble prodrugs. Molecules 2011, 16, 6769-6777.

17. Thomas, M.; Rivault, F.; Tranoy-Opalinski, I.; Roche, J.; Gesson, J.-P.; Papot, S. Synthesis and biological evaluation of the suberoylanilide hydroxamic acid (SAHA) $\beta$-glucuronide and $\beta$-galactoside for application in selective prodrug chemotherapy. Bioorg. Med. Chem. Lett. 2007, 17, 983-986.

18. Giorgioni, G.; Ruggieri, S.; di Stefano, A.; Sozio, P.; Cinque, B.; di Marzio, L.; Santoni, G.; Claudi, F. Glycosyl and polyalcoholic prodrugs of lonidamine. Bioorg. Med. Chem. Lett. 2008, 18, 2445-2450.

19. Houba, P.; Boven, E.; van der Meulen-Muileman, I.; Leenders, R.; Scheeren, J.; Pinedo, H.; Haisma, H. A novel doxorubicin-glucuronide prodrug DOX-GA3 for tumour-selective chemotherapy: Distribution and efficacy in experimental human ovarian cancer. Br. J. Cancer 2001, 84, 550-557.

20. Brown, R.S.; Wahl, R.L. Overexpression of glut-1 glucose transporter in human breast cancer an immunohistochemical study. Cancer 1993, 72, 2979-2985.

21. Fernández, C.; Nieto, O.; Fontenla, J.A.; Rivas, E.; de Ceballos, M.L.; Fernández-Mayoralas, A. Synthesis of glycosyl derivatives as dopamine prodrugs: Interaction with glucose carrier GLUT-1. Org. Biomol. Chem. 2003, 1, 767-771.

22. Fernández, C.; Nieto, O.; Rivas, E.; Montenegro, G.; Fontenla, J.A.; Fernández-Mayoralas, A. Synthesis and biological studies of glycosyl dopamine derivatives as potential antiparkinsonian agents. Carbohydr. Res. 2000, 327, 353-365.

23. Rodriguez, M.C.; Cudic, M. Optimization of physicochemical and pharmacological properties of Peptide drugs by glycosylation. In Peptide Modifications to Increase Metabolic Stability and Activity; Cudic, R., Ed.; Humana Press: New York City, NY, USA, 2013; pp. 107-136.

24. Polt, R.; Porreca, F.; Szabo, L.Z.; Bilsky, E.J.; Davis, P.; Abbruscato, T.J.; Davis, T.P.; Harvath, R.; Yamamura, H.I.; Hruby, V.J. Glycopeptide enkephalin analogues produce analgesia in mice: Evidence for penetration of the blood-brain barrier. Proc. Natl. Acad. Sci. USA 1994, 91, 7114-7118.

25. Fahr, A.; Liu, X. Drug delivery strategies for poorly water-soluble drugs. Expert Opin. Drug Deliv. 2007, 4, 403-416.

26. Douroumis, D.; Fahr, A. Drug Delivery Strategies for Poorly Water-Soluble Drugs; John Wiley \& Sons: Weinheim, Germany, 2012. 
27. Sahoo, S.K.; Jain, T.K.; Reddy, M.K.; Labhasetwar, V. Nano-sized carriers for drug delivery. In NanoBioTechnology; Humana Press: New York City, NY, USA, 2008; pp. 329-348.

28. Jain, K.; Kesharwani, P.; Gupta, U.; Jain, N.K. A review of glycosylated carriers for drug delivery. Biomaterials 2012, 33, 4166-4186.

29. Monsigny, M.; Roche, A.-C.; Midoux, P.; Mayer, R. Glycoconjugates as carriers for specific delivery of therapeutic drugs and genes. Adv. Drug Deliv. Rev. 1994, 14, 1-24.

30. Agrawal, P.; Gupta, U.; Jain, N. Glycoconjugated peptide dendrimers-based nanoparticulate system for the delivery of chloroquine phosphate. Biomaterials 2007, 28, 3349-3359.

31. Jain, S.; Vyas, S. Mannosylated niosomes as adjuvant-carrier system for oral mucosal immunization. J. Liposome Res. 2006, 16, 331-345.

32. Stewart, A.; Pichon, C.; Meunier, L.; Midoux, P.; Monsigny, M.; Roche, A. Enhanced biological activity of antisense oligonucleotides complexed with glycosylated poly-L-lysine. Mol. Pharmacol. 1996, 50, 1487-1494.

33. Cramer, F. Einschlussverbindungen; Springer: Berlin, Germany, 1954.

34. Loftsson, T.; Duchene, D. Cyclodextrins and their pharmaceutical applications. Int. J. Pharm. 2007, 329, 1-11.

35. Schardinger, F. Bildung kristallisierter polysaccharide (dextrine) aus stärkekleister durch microben. Zentr. Bakt. Parasit. Abt. II 1911, 29, 188-197.

36. Freudenberg, K.; Cramer, F.; Plieninger, H. Verfahren zur Herstellung von Einschlussverbindungen Physiologisch Wirksamer Organischer Verbindungen. German Patent DE895769C, 5 November 1953.

37. Salústio, P.; Cabral-Marques, H.; Costa, P.; Pinto, J. Comparison of ibuprofen release from minitablets and capsules containing ibuprofen: $\beta$-Cyclodextrin complex. Eur. J. Pharm. Biopharm. 2011, 78, 58-66.

38. Cartledge, J.; Midgley, J.; Youle, M.; Gazzard, B. Itraconazole cyclodextrin solution-Effective treatment for HIV-related candidosis unresponsive to other azole therapy. J. Antimicrob. Chemother. 1994, 33, 1071-1073.

39. Ficarra, R.; Ficarra, P.; di Bella, M.; Raneri, D.; Tommasini, S.; Calabro, M.; Villari, A.; Coppolino, S. Study of the inclusion complex of atenolol with $\beta$-cyclodextrins. J. Pharm. Biomed. Anal. 2000, 23, 231-236.

40. Manca, M.L.; Zaru, M.; Ennas, G.; Valenti, D.; Sinico, C.; Loy, G.; Fadda, A.M. Diclofenac- $\beta$ cyclodextrin binary systems: Physicochemical characterization and in vitro dissolution and diffusion studies. AAPS PharmSciTech 2005, 6, E464-E472.

41. Naidoo, K.J.; Chen, J.Y.-J.; Jansson, J.L.; Widmalm, G.; Maliniak, A. Molecular properties related to the anomalous solubility of $\beta$-cyclodextrin. J. Phys. Chem. B 2004, 108, 4236-4238.

42. Brewster, M.E.; Loftsson, T. Cyclodextrins as pharmaceutical solubilizers. Adv. Drug Deliv. Rev. 2007, 59, 645-666.

43. Davis, M.E.; Brewster, M.E. Cyclodextrin-based pharmaceutics: Past, present and future. Nat. Rev. Drug Discov. 2004, 3, 1023-1035.

44. Gould, S.; Scott, R.C. 2-Hydroxypropyl- $\beta$-cyclodextrin (HP- $\beta$-CD): A toxicology review. Food Chem. Toxicol. 2005, 43, 1451-1459.

45. Irie, T.; Uekama, K. Pharmaceutical applications of cyclodextrins. III. Toxicological issues and safety evaluation. J. Pharm. Sci. 1997, 86, 147-162. 
46. Cserháti, T. Interaction of some anticancer drugs with carboxymethyl- $\beta$-cyclodextrin. Int. J. Pharm. 1995, 124, 205-211.

47. Liu, Y.; Chen, Y. Cooperative binding and multiple recognition by bridged bis ( $\beta$-cyclodextrin)s with functional linkers. Acc. Chem. Res. 2006, 39, 681-691.

48. Lu, Z.; Lu, C.; Ren, X.; Meng, Q. New metallocene-bridged cyclodextrin dimer: A stable derivative of the antitumor drug titanocene dichloride and its potent cytotoxity against human breast cancer (MCF-7) cells. J. Organomet. Chem. 2006, 691, 5895-5899.

49. Liu, Y.; Chen, G.-S.; Li, L.; Zhang, H.-Y.; Cao, D.-X.; Yuan, Y.-J. Inclusion complexation and solubilization of paclitaxel by bridged bis ( $\beta$-cyclodextrin)s containing a tetraethylenepentaamino spacer. J. Med. Chem. 2003, 46, 4634-4637.

50. French, D. The schardinger dextrins. Adv. Carbohydr. Chem. 1957, 12, 189-260.

51. Fujiwara, T.; Tanaka, N.; Kobayashi, S. Structure of. DELTA.-cyclodextrin $13.75 \mathrm{H}_{2} \mathrm{O}$. Chem. Lett. 1990, 739-742.

52. Miyazawa, I.; Ueda, H.; Nagase, H.; Endo, T.; Kobayashi, S.; Nagai, T. Physicochemical properties and inclusion complex formation of $\delta$-cyclodextrin. Eur. J. Pharm. Sci. 1995, 3, 153-162.

53. Jacob, J.; Geßler, K.; Hoffmann, D.; Sanbe, H.; Koizumi, K.; Smith, S.M.; Takaha, T.; Saenger, W. Band-flip and kink as novel structural motifs in $\alpha-(1 \rightarrow 4)$-D-glucose oligosaccharides. Crystal structures of cyclodeca-and cyclotetradecaamylose. Carbohydr. Res. 1999, 322, 228-246.

54. Nimz, O.; Geßler, K.; Usón, I.; Saenger, W. An orthorhombic crystal form of cyclohexaicosaose, CA26 $\cdots 32.59 \mathrm{H}_{2} \mathrm{O}$ : Comparison with the triclinic form. Carbohydr. Res. 2001, 336, 141-153.

55. Larsen, K.L. Large cyclodextrins. J. Incl. Phenom. Macrocycl. Chem. 2002, 43, 1-13.

56. Koizumi, K.; Okada, Y.; Horiyama, S.; Utamura, T.; Higashiura, T.; Ikeda, M. Preparation of cyclosophoraose-A and its complex-forming ability. In Clathrate Compounds, Molecular Inclusion Phenomena, and Cyclodextrins; Springer: New York City, NY, USA, 1984; pp. 891-899.

57. Lee, S.; Kwon, C.; Choi, Y.; Seo, D.-H.; Kim, H.-W.; Jung, S. Inclusion complexation of a family of cyclosophoraoses with indomethacin. J. Microbiol. Biotechnol. 2001, 11, 463-468.

58. Lee, S.; Seo, D.-H.; Kim, H.-W.; Jung, S. Investigation of inclusion complexation of paclitaxel by cyclohenicosakis- $(1 \rightarrow 2)$-( $\beta$-D-glucopyranosyl), by cyclic- $(1 \rightarrow 2)-\beta$-D-glucans (cyclosophoraoses), and by cyclomaltoheptaoses ( $\beta$-cyclodextrins). Carbohydr. Res. 2001, 334, 119-126.

59. Lee, S.; Seo, D.-H.; Park, H.-L.; Choi, Y.; Jung, S. Solubility enhancement of a hydrophobic flavonoid, luteolin by the complexation with cyclosophoraoses isolated from Rhizobium meliloti. Antonie Leeuwenhoek 2003, 84, 201-207.

60. Kim, H.; Jeong, K.; Lee, S.; Jung, S. Molecular dynamics simulation of cyclosophoroheptadecaose (Cys-A). J. Comput. Aided Mol. Des. 2002, 16, 601-610.

61. Mimura, M.; Kitamura, S.; Gotoh, S.; Takeo, K.; Urakawa, H.; Kajiwara, K. Conformation of cyclic and linear $(1 \rightarrow 2)-\beta$-D-glucans in aqueous solution. Carbohydr. Res. 1996, 289, 25-37.

62. Lee, S.; Park, H.; Seo, D.; Choi, Y.; Jung, S. Synthesis and characterization of carboxymethylated cyclosophoraose, and its inclusion complexation behavior. Carbohydr. Res. 2004, 339, 519-527.

63. Park, H.; Jung, S. Separation of some chiral flavonoids by microbial cyclosophoraoses and their sulfated derivatives in micellar electrokinetic chromatography. Electrophoresis 2005, 26, 3833-3838. 
64. Kim, H.; Choi, J.M.; Choi, Y.; Tahir, M.N.; Yang, Y.-H.; Cho, E.; Jung, S. Enhanced solubility of galangin based on the complexation with methylated microbial cyclosophoraoses. J. Incl. Phenom. Macrocycl. Chem. 2014, 79, 291-300.

65. Piao, J.; Jang, A.; Choi, Y.; Tahir, M.N.; Kim, Y.; Park, S.; Cho, E.; Jung, S. Solubility enhancement of $\alpha$-naphthoflavone by synthesized hydroxypropyl cyclic-( $1 \rightarrow 2)-\beta$-D-glucans (cyclosophoroases). Carbohydr. Polym. 2014, 101, 733-740.

66. Jeong, D.; Choi, J.M.; Choi, Y.; Jeong, K.; Cho, E.; Jung, S. Complexation of fisetin with novel cyclosophoroase dimer to improve solubility and bioavailability. Carbohydr. Polym. 2013, 97, 196-202.

67. Eggens, I.; Fenderson, B.; Toyokuni, T.; Dean, B.; Stroud, M.; Hakomori, S.-I. Specific interaction between Lex and Lex determinants. A possible basis for cell recognition in preimplantation embryos and in embryonal carcinoma cells. J. Biol. Chem. 1989, 264, 9476-9484.

68. Vyas, N.K. Atomic features of protein-carbohydrate interactions. Curr. Opin. Struct. Biol. 1991, $1,732-740$.

69. Aoyama, Y.; Otsuki, J.-I.; Nagai, Y.; Kobayashi, K.; Toi, H. Host-guest complexation of oligosaccharides: Interaction of maltodextrins with hydrophobic fluorescence probes in water. Tetrahedron Lett. 1992, 33, 3775-3778.

70. Kim, H.; Kim, K.; Choi, J.M.; Tahir, M.N.; Cho, E.; Choi, Y.; Lee, I.-S.; Jung, S. Solubilization of pyrimethamine, antibacterial drug, by low-molecular-weight succinoglycan dimers isolated from Shinorhizobium meliloti. Bull. Korean Chem. Soc. 2012, 33, doi:10.5012/bkcs.2012.33.8.2731.

71. Choi, J.M.; Kim, H.; Cho, E.; Choi, Y.; Jung, S. Solubilization of haloperidol by acyclic succinoglycan oligosaccharides. Carbohydr. Polym. 2012, 89, 564-570.

72. Cho, E.; Choi, J.M.; Jung, S. Solubility enhancement of isoflavonoids by complexation with acyclic hexadecasaccharides, succinoglycan dimers isolated from Sinorhizobium meliloti. J. Incl. Phenom. Macrocycl. Chem. 2013, 76, 133-141.

73. Kim, K.; Cho, E.; Choi, J.M.; Kim, H.; Jang, A.; Choi, Y.; Yu, J.-H.; Jung, S. Intermolecular complexation of low-molecular-weight succinoglycans directs solubility enhancement of pindolol. Carbohydr. Polym. 2014, 106, 101-108.

74. Ma, D.; Hettiarachchi, G.; Nguyen, D.; Zhang, B.; Wittenberg, J.B.; Zavalij, P.Y.; Briken, V.; Isaacs, L. Acyclic cucurbit[ $n]$ uril molecular containers enhance the solubility and bioactivity of poorly soluble pharmaceuticals. Nat. Chem. 2012, 4, 503-510.

75. Moyano, J.; Ginés, J.; Arias, M.; Rabasco, A. Study of the dissolution characteristics of oxazepam via complexation with $\beta$-cyclodextrin. Int. J. Pharm. 1995, 114, 95-102.

76. Pose-Vilarnovo, B.; Perdomo-López, I.; Echezarreta-López, M.; Schroth-Pardo, P.; Estrada, E.; Torres-Labandeira, J.J. Improvement of water solubility of sulfamethizole through its complexation with $\beta$-and hydroxypropyl- $\beta$-cyclodextrin: Characterization of the interaction in solution and in solid state. Eur. J. Pharm. Sci. 2001, 13, 325-331.

77. Yáñez, C.; Cañete-Rosales, P.; Castillo, J.P.; Catalán, N.; Undabeytia, T.; Morillo, E. Cyclodextrin inclusion complex to improve physicochemical properties of herbicide bentazon: Exploring better formulations. PLoS ONE 2012, 7, e41072. 
78. Moyano, J.; Arias, M.; Gines, J.; Perez, J.; Rabasco, A. Dissolution Behavior of Oxazepam in Presence of Cyclodextrins: Evaluation of Oxazepam-Dimeb Binary Systemxs. Drug Dev. Ind. Pharm. 1997, 23, 379-385.

79. Schneider, H.-J.; Hacket, F.; Rüdiger, V.; Ikeda, H. NMR studies of cyclodextrins and cyclodextrin complexes. Chem. Rev. 1998, 98, 1755-1786.

80. Ishizuka, Y.; Fujiwara, M.; Kanazawa, K.; Nemoto, T.; Fujita, K.-I.; Nakanishi, H. Three-dimensional structure of the inclusion complex between phloridzin and $\beta$-cyclodextrin. Carbohydr. Res. 2002, 337, 1737-1743.

81. Pînzaru, I.; Hadaruga, D.; Hadaruga, N.; Corpa, L.; Grozescu, I.; Peter, F. Hepatoprotective flavonoid bioconjugate/ $\beta$-cyclodextrin nanoparticles: DSC-molecular modeling correlation. Dig. J. Nanomater. Biostruct. 2011, 6, 1605-1617.

82. Bilensoy, E.; Doğan, L.; Şen, M.; Hıncal, A. Complexation behavior of antiestrogen drug tamoxifen citrate with natural and modified $\beta$-cyclodextrins. J. Incl. Phenom. Macrocycl. Chem. 2007, 57, 651-655.

83. Sinha, V.; Anitha, R.; Ghosh, S.; Nanda, A.; Kumria, R. Complexation of celecoxib with $\beta$-cyclodextrin: Characterization of the interaction in solution and in solid state. J. Pharm. Sci. 2005, 94, 676-687.

84. Al Omari, M.M.; Zughul, M.B.; Davies, J.E.D.; Badwan, A.A. Sildenafil/cyclodextrin complexation: Stability constants, thermodynamics, and guest-host interactions probed by $1 \mathrm{H}-\mathrm{NMR}$ and molecular modeling studies. J. Pharm. Biomed. Anal. 2006, 41, 857-865.

85. Higuchi, T.; Connors, A. Phase-solubility techniques. In Advances in Analytical Chemistry and Instrumentation; Jonh Wiley \& Sons: Weinheim, Germany, 1965.

86. Loftsson, T.; Magnúsdóttir, A.; Másson, M.; Sigurjónsdóttir, J.F. Self-association and cyclodextrin solubilization of drugs. J. Pharm. Sci. 2002, 91, 2307-2316.

87. Connors, K.A. The stability of cyclodextrin complexes in solution. Chem. Rev. 1997, 97, 1325-1358.

88. Stella, V.J.; Rao, V.M.; Zannou, E.A.; Zia, V. Mechanisms of drug release from cyclodextrin complexes. Adv. Drug Deliv. Rev. 1999, 36, 3-16.

89. Loftsson, T.; Moya-Ortega, M.D.; Alvarez-Lorenzo, C.; Concheiro, A. Pharmacokinetics of cyclodextrins and drugs after oral and parenteral administration of drug/cyclodextrin complexes. J. Pharm. Pharmacol. 2015, doi:10.1111/jphp.12427.

90. Yao, Y.; Xie, Y.; Hong, C.; Li, G.; Shen, H.; Ji, G. Development of a myricetin/hydroxypropyl- $\beta$ cyclodextrin inclusion complex: Preparation, characterization, and evaluation. Carbohydr. Polym. 2014, 110, 329-337.

91. Lin, H.-S.; Leong, W.W.Y.; Yang, J.A.; Lee, P.; Chan, S.Y.; Ho, P.C. Biopharmaceutics of 13-cis-retinoic acid (isotretinoin) formulated with modified $\beta$-cyclodextrins. Int. J. Pharm. 2007, 341, 238-245.

92. Leonardi, D.; Bombardiere, M.; Salomon, C. Effects of benznidazole: Cyclodextrin complexes on the drug bioavailability upon oral administration to rats. Int. J. Biol. Macromol. 2013, 62, 543-548.

93. Sinha, V.R. In vivo bioavailability and therapeutic assessment of host-guest inclusion phenomena for the hydrophobic molecule etodolac: Pharmacodynamic and pharmacokinetic evaluation. Sci. Pharm. 2010, 78, 103-115.

94. Kurkov, S.V.; Loftsson, T. Cyclodextrins. Int. J. Pharm. 2013, 453, 167-180. 
95. Pokharkar, V.; Khanna, A.; Venkatpurwar, V.; Dhar, S.; Mandpe, L. Ternary complexation of carvedilol, $\beta$-cyclodextrin and citric acid for mouth-dissolving tablet formulation. Acta Pharm. 2009, 59, 121-132.

96. Dua, K.; Ramana, M.; Singh Sara, U.; Himaja, M.; Agrawal, A.; Garg, V.; Pabreja, K. Investigation of enhancement of solubility of norfloxacin $\beta$-cyclodextrin in presence of acidic solubilizing additives. Curr. Drug Deliv. 2007, 4, 21-25.

97. Mura, P.; Maestrelli, F.; Cirri, M. Ternary systems of naproxen with hydroxypropyl- $\beta$-cyclodextrin and aminoacids. Int. J. Pharm. 2003, 260, 293-302.

98. Li, P.; Zhao, L.; Yalkowsky, S.H. Combined effect of cosolvent and cyclodextrin on solubilization of nonpolar drugs. J. Pharm. Sci. 1999, 88, 1107-1111.

99. Loftsson, T.; Másson, M. The effects of water-soluble polymers on cyclodextrins and cyclodextrin solubilization of drugs. J. Drug Deliv. Sci. Technol. 2004, 14, 35-43.

100. Wang, D.; Li, H.; Gu, J.; Guo, T.; Yang, S.; Guo, Z.; Zhang, X.; Zhu, W.; Zhang, J. Ternary system of dihydroartemisinin with hydroxypropyl- $\beta$-cyclodextrin and lecithin: Simultaneous enhancement of drug solubility and stability in aqueous solutions. J. Pharm. Biomed. Anal. 2013, 83, 141-148.

101. Sallas, F.; Darcy, R. Amphiphilic cyclodextrins-advances in synthesis and supramolecular chemistry. Eur. J. Org. Chem. 2008, 2008, 957-969.

102. Zhang, J.; Ma, P.X. Cyclodextrin-based supramolecular systems for drug delivery: Recent progress and future perspective. Adv. Drug Deliv. Rev. 2013, 65, 1215-1233.

103. Auzely-Velty, R.; Djedaini-Pilard, F.; Desert, S.; Perly, B.; Zemb, T. Micellization of hydrophobically modified cyclodextrins. 1. Micellar structure. Langmuir 2000, 16, 3727-3734.

104. Donohue, R.; Mazzaglia, A.; Ravoo, B.J.; Darcy, R. Cationic $\beta$-cyclodextrin bilayer vesicles. Chem. Commun. 2002, 2864-2865.

105. Kawabata, Y.; Matsumoto, M.; Tanaka, M.; Takahashi, H.; Irinatsu, Y.; Tamura, S.; Tagaki, W.; Nakahara, H.; Fukuda, K. Formation and deposition of monolayers of amphiphilic. $\beta$-cyclodextrin derivatives. Chem. Lett. 1986, 1933-1934.

106. Quaglia, F.; Ostacolo, L.; Mazzaglia, A.; Villari, V.; Zaccaria, D.; Sciortino, M.T. The intracellular effects of non-ionic amphiphilic cyclodextrin nanoparticles in the delivery of anticancer drugs. Biomaterials 2009, 30, 374-382.

107. Sun, T.; Guo, Q.; Zhang, C.; Hao, J.; Xing, P.; Su, J.; Li, S.; Hao, A.; Liu, G. Self-assembled vesicles prepared from amphiphilic cyclodextrins as drug carriers. Langmuir 2012, 28, 8625-8636.

108. Perret, F.; Duffour, M.; Chevalier, Y.; Parrot-Lopez, H. Design, synthesis, and in vitro evaluation of new amphiphilic cyclodextrin-based nanoparticles for the incorporation and controlled release of acyclovir. Eur. J. Pharm. Biopharm. 2013, 83, 25-32.

109. Van de Manakker, F.; Vermonden, T.; van Nostrum, C.F.; Hennink, W.E. Cyclodextrin-based polymeric materials: Synthesis, properties, and pharmaceutical/biomedical applications. Biomacromolecules 2009, 10, 3157-3175.

110. Szeman, J.; Fenyvesi, E.; Szejtli, J.; Ueda, H.; Machida, Y.; Nagai, T. Water soluble cyclodextrin polymers: Their interaction with drugs. In Proceedings of the Fourth International Symposium on Inclusion Phenomena and the Third International Symposium on Cyclodextrins, Lancaster, UK, 20-25 July 1986; Atwood, J.L., Davies, J.E., Eds.; Springer: New York City, NY, USA 1987; pp. 319-323. 
111. Ma, M.; Li, D. Cyclodextrin Polymer Separation Materials. WO1998022197A9, 28 May 1998.

112. Trotta, F.; Zanetti, M.; Cavalli, R. Cyclodextrin-based nanosponges as drug carriers. Beilstein J. Org. Chem. 2012, 8, 2091-2099.

113. Zhou, J.; Ritter, H. Cyclodextrin functionalized polymers as drug delivery systems. Polym. Chem. 2010, 1, 1552-1559.

114. Gil, E.S.; Li, J.; Xiao, H.; Lowe, T.L. Quaternary ammonium $\beta$-cyclodextrin nanoparticles for enhancing doxorubicin permeability across the in vitro blood-brain barrier. Biomacromolecules 2009, 10, 505-516.

115. Qiu, L.Y.; Wang, R.J.; Zheng, C.; Jin, Y.; Jin, L.Q. $\beta$-cyclodextrin-centered star-shaped amphiphilic polymers for doxorubicin delivery. Nanomed. Nanotechnol. Biol. Med. 2010, 5, 193-208.

116. Posocco, B.; Dreussi, E.; de Santa, J.; Toffoli, G.; Abrami, M.; Musiani, F.; Grassi, M.; Farra, R.; Tonon, F.; Grassi, G. Polysaccharides for the delivery of antitumor drugs. Materials 2015, 8, 2569-2615.

117. Ringsdorf, H. Structure and properties of pharmacologically active polymers. J. Polym. Sci. Polym. Symp. 1975, 51, 135-153.

118. Bassi, P.; Volpe, A.; D’Agostino, D.; Palermo, G.; Renier, D.; Franchini, S.; Rosato, A.; Racioppi, M. Paclitaxel-hyaluronic acid for intravesical therapy of bacillus Calmette-Guerin refractory carcinoma in situ of the bladder: Results of a phase I study. J. Urol. 2011, 185, 445-449.

119. Mero, A.; Campisi, M. Hyaluronic acid bioconjugates for the delivery of bioactive molecules. Polymers 2014, 6, 346-369.

120. Yousefpour, P.; Atyabi, F.; Farahani, E.V.; Sakhtianchi, R.; Dinarvand, R. Polyanionic carbohydrate doxorubicin-dextran nanocomplex as a delivery system for anticancer drugs: In vitro analysis and evaluations. Int. J. Nanomed. 2011, 6, 1487-1496.

121. Yousefpour, P.; Atyabi, F.; Vasheghani-Farahani, E.; Movahedi, A.-A.M.; Dinarvand, R. Targeted delivery of doxorubicin-utilizing chitosan nanoparticles surface-functionalized with anti-Her2 trastuzumab. Int. J. Nanomed. 2011, 6, 1977-1990.

122. Wang, Y.; Xin, D.; Liu, K.; Zhu, M.; Xiang, J. Heparin-paclitaxel conjugates as drug delivery system: Synthesis, self-assembly property, drug release, and antitumor activity. Bioconjug. Chem. 2009, 20, 2214-2221.

123. Al-Shamkhani, A.; Duncan, R. Synthesis, controlled release properties and antitumour activity of alginate-cis-aconityl-daunomycin conjugates. Int. J. Pharm. 1995, 122, 107-119.

124. Zhang, H.; Li, F.; Yi, J.; Gu, C.; Fan, L.; Qiao, Y.; Tao, Y.; Cheng, C.; Wu, H. Folate-decorated maleilated pullulan-doxorubicin conjugate for active tumor-targeted drug delivery. Eur. J. Pharm. Sci. 2011, 42, 517-526.

125. Elgart, A.; Farber, S.; Domb, A.J.; Polacheck, I.; Hoffman, A. Polysaccharide pharmacokinetics: Amphotericin B arabinogalactan conjugate-A drug delivery system or a new pharmaceutical entity? Biomacromolecules 2010, 11, 1972-1977.

126. Pinhassi, R.I.; Assaraf, Y.G.; Farber, S.; Stark, M.; Ickowicz, D.; Drori, S.; Domb, A.J.; Livney, Y.D. Arabinogalactan-folic acid-drug conjugate for targeted delivery and target-activated release of anticancer drugs to folate receptor-overexpressing cells. Biomacromolecules 2009, 11, 294-303.

127. Goodarzi, N.; Varshochian, R.; Kamalinia, G.; Atyabi, F.; Dinarvand, R. A review of polysaccharide cytotoxic drug conjugates for cancer therapy. Carbohydr. Polym. 2013, 92, 1280-1293. 
128. Ahrens, T.; Assmann, V.; Fieber, C.; Termeer, C.C.; Herrlich, P.; Hofmann, M.; Simon, J.C. CD44 is the principal mediator of hyaluronic-acid-induced melanoma cell proliferation. J. Investig. Dermatol. 2001, 116, 93-101.

129. Lamke, L.-O.; Liljedahl, S.-O. Plasma volume changes after infusion of various plasma expanders. Resuscitation 1976, 5, 93-102.

130. Soepenberg, O.; de Jonge, M.J.; Sparreboom, A.; de Bruin, P.; Eskens, F.A.; de Heus, G.; Wanders, J.; Cheverton, P.; Ducharme, M.P.; Verweij, J. Phase I and pharmacokinetic study of DE-310 in patients with advanced solid tumors. Clin. Cancer Res. 2005, 11, 703-711.

131. Veltkamp, S.A.; Witteveen, E.O.; Capriati, A.; Crea, A.; Animati, F.; Voogel-Fuchs, M.; van den Heuvel, I.J.; Beijnen, J.H.; Voest, E.E.; Schellens, J.H. Clinical and pharmacologic study of the novel prodrug delimotecan (MEN 4901/T-0128) in patients with solid tumors. Clin. Cancer Res. 2008, 14, 7535-7544.

132. Danhauser-Riedl, S.; Hausmann, E.; Schick, H.-D.; Bender, R.; Dietzfelbinger, H.; Rastetter, J.; Hanauske, A.-R. Phase I clinical and pharmacokinetic trial of dextran conjugated doxorubicin (AD-70, DOX-OXD). Investig. New Drugs 1993, 11, 187-195.

133. Mahajan, H.S.; Tyagi, V.; Lohiya, G.; Nerkar, P. Thermally reversible xyloglucan gels as vehicles for nasal drug delivery. Drug Deliv. 2012, 19, 270-276.

134. Miyazaki, S.; Suisha, F.; Kawasaki, N.; Shirakawa, M.; Yamatoya, K.; Attwood, D. Thermally reversible xyloglucan gels as vehicles for rectal drug delivery. J. Control. Release 1998, 56, 75-83.

135. Suisha, F.; Kawasaki, N.; Miyazaki, S.; Shirakawa, M.; Yamatoya, K.; Sasaki, M.; Attwood, D. Xyloglucan gels as sustained release vehicles for the intraperitoneal administration of mitomycin C. Int. J. Pharm. 1998, 172, 27-32.

136. Kawasaki, N.; Ohkura, R.; Miyazaki, S.; Uno, Y.; Sugimoto, S.; Attwood, D. Thermally reversible xyloglucan gels as vehicles for oral drug delivery. Int. J. Pharm. 1999, 181, 227-234.

137. Joshi, S.C. Sol-Gel behavior of hydroxypropyl methylcellulose (hpmc) in ionic media including drug release. Materials 2011, 4, 1861-1905.

138. Zahoor, A.; Sharma, S.; Khuller, G. Inhalable alginate nanoparticles as antitubercular drug carriers against experimental tuberculosis. Int. J. Antimicrob. Agents 2005, 26, 298-303.

139. Rajaonarivony, M.; Vauthier, C.; Couarraze, G.; Puisieux, F.; Couvreur, P. Development of a new drug carrier made from alginate. J. Pharm. Sci. 1993, 82, 912-917.

140. Dai, Y.N.; Li, P.; Zhang, J.P.; Wang, A.Q.; Wei, Q. A novel pH sensitive N-succinyl chitosan/alginate hydrogel bead for nifedipine delivery. Biopharm. Drug Dispos. 2008, 29, 173-184.

141. Wang, C.; Liu, H.; Gao, Q.; Liu, X.; Tong, Z. Alginate-calcium carbonate porous microparticle hybrid hydrogels with versatile drug loading capabilities and variable mechanical strengths. Carbohydr. Polym. 2008, 71, 476-480.

142. Jain, D.; Banerjee, R. Comparison of ciprofloxacin hydrochloride-loaded protein, lipid, and chitosan nanoparticles for drug delivery. J. Biomed. Mater. Res. B Appl. Biomater. 2008, 86, 105-112.

143. Maestrelli, F.; Garcia-Fuentes, M.; Mura, P.; Alonso, M.J. A new drug nanocarrier consisting of chitosan and hydoxypropylcyclodextrin. Eur. J. Pharm. Biopharm. 2006, 63, 79-86.

144. Lin, W.-C.; Yu, D.-G.; Yang, M.-C. pH-sensitive polyelectrolyte complex gel microspheres composed of chitosan/sodium tripolyphosphate/dextran sulfate: Swelling kinetics and drug delivery properties. Colloids Surf. B Biointerfaces 2005, 44, 143-151. 
145. Tiyaboonchai, W.; Limpeanchob, N. Formulation and characterization of amphotericin B-chitosandextran sulfate nanoparticles. Int. J. Pharm. 2007, 329, 142-149.

146. Zheng, Y.; Wu, Y.; Yang, W.; Wang, C.; Fu, S.; Shen, X. Preparation, characterization, and drug release in vitro of chitosan-glycyrrhetic acid nanoparticles. J. Pharm. Sci. 2006, 95, 181-191.

147. Ruel-Gariépy, E.; Shive, M.; Bichara, A.; Berrada, M.; le Garrec, D.; Chenite, A.; Leroux, J.-C. A thermosensitive chitosan-based hydrogel for the local delivery of paclitaxel. Eur. J. Pharm. Biopharm. 2004, 57, 53-63.

148. Cheow, W.S.; Kiew, T.Y.; Hadinoto, K. Amorphous nanodrugs prepared by complexation with polysaccharides: Carrageenan versus dextran sulfate. Carbohydr. Polym. 2015, 117, 549-558.

149. Cho, H.-J.; Yoon, H.Y.; Koo, H.; Ko, S.-H.; Shim, J.-S.; Lee, J.-H.; Kim, K.; Kwon, I.C.; Kim, D.-D. Self-assembled nanoparticles based on hyaluronic acid-ceramide (HA-CE) and Pluronic ${ }^{\circledR}$ for tumor-targeted delivery of docetaxel. Biomaterials 2011, 32, 7181-7190.

150. Cho, H.-J.; Yoon, I.-S.; Yoon, H.Y.; Koo, H.; Jin, Y.-J.; Ko, S.-H.; Shim, J.-S.; Kim, K.; Kwon, I.C.; Kim, D.-D. Polyethylene glycol-conjugated hyaluronic acid-ceramide self-assembled nanoparticles for targeted delivery of doxorubicin. Biomaterials 2012, 33, 1190-1200.

151. Li, J.; Huo, M.; Wang, J.; Zhou, J.; Mohammad, J.M.; Zhang, Y.; Zhu, Q.; Waddad, A.Y.; Zhang, Q. Redox-sensitive micelles self-assembled from amphiphilic hyaluronic acid-deoxycholic acid conjugates for targeted intracellular delivery of paclitaxel. Biomaterials 2012, 33, 2310-2320.

152. Wu, J.-L.; Liu, C.-G.; Wang, X.-L.; Huang, Z.-H. Preparation and characterization of nanoparticles based on histidine-hyaluronic acid conjugates as doxorubicin carriers. J. Mater. Sci. Mater. Med. 2012, 23, 1921-1929.

153. Kumar, B.S.; Kumar, M.G.; Suguna, L.; Sastry, T.; Mandal, A. Pullulan acetate nanoparticles based delivery system for hydrophobic drug. Int. J. Pharma Biol. Sci. 2012, 3, 24-32.

154. Wang, Y.-S.; Liu, L.-R.; Jiang, Q.; Zhang, Q.-Q. Self-aggregated nanoparticles of cholesterol-modified chitosan conjugate as a novel carrier of epirubicin. Eur. Polym. J. 2007, 43, 43-51.

155. Lee, K.; Kim, J.-H.; Kwon, I.; Jeong, S. Self-aggregates of deoxycholic acid-modified chitosan as a novel carrier of adriamycin. Colloid Polym. Sci. 2000, 278, 1216-1219.

156. Jin, Y.-H.; Hu, H.-Y.; Qiao, M.-X.; Zhu, J.; Qi, J.-W.; Hu, C.-J.; Zhang, Q.; Chen, D.-W. $\mathrm{pH}$-sensitive chitosan-derived nanoparticles as doxorubicin carriers for effective anti-tumor activity: Preparation and in vitro evaluation. Colloids Surf. B Biointerfaces 2012, 94, 184-191.

157. Kim, J.-H.; Kim, Y.-S.; Kim, S.; Park, J.H.; Kim, K.; Choi, K.; Chung, H.; Jeong, S.Y.; Park, R.-W.; Kim, I.-S. Hydrophobically modified glycol chitosan nanoparticles as carriers for paclitaxel. J. Control. Release 2006, 111, 228-234.

158. Min, K.H.; Park, K.; Kim, Y.-S.; Bae, S.M.; Lee, S.; Jo, H.G.; Park, R.-W.; Kim, I.-S.; Jeong, S.Y.; Kim, K. Hydrophobically modified glycol chitosan nanoparticles-encapsulated camptothecin enhance the drug stability and tumor targeting in cancer therapy. J. Control. Release 2008, 127, 208-218.

159. Yuan, H.; Lu, L.-J.; Du, Y.-Z.; Hu, F.-Q. Stearic acid-g-chitosan polymeric micelle for oral drug delivery: In vitro transport and in vivo absorption. Mol. Pharm. 2010, 8, 225-238.

160. Xie, Y.-T.; Du, Y.-Z.; Yuan, H.; Hu, F.-Q. Brain-targeting study of stearic acid-grafted chitosan micelle drug-delivery system. Int. J. Nanomed. 2012, 7, 3235-3244. 
161. Park, J.S.; Han, T.H.; Lee, K.Y.; Han, S.S.; Hwang, J.J.; Moon, D.H.; Kim, S.Y.; Cho, Y.W. $\mathrm{N}$-acetyl histidine-conjugated glycol chitosan self-assembled nanoparticles for intracytoplasmic delivery of drugs: Endocytosis, exocytosis and drug release. J. Control. Release 2006, 115, 37-45.

162. Xu, Q.; Yuan, X.; Chang, J. Self-aggregates of cholic acid hydrazide-dextran conjugates as drug carriers. J. Appl. Polym. Sci. 2005, 95, 487-493.

163. Daoud-Mahammed, S.; Couvreur, P.; Bouchemal, K.; Chéron, M.; Lebas, G.; Amiel, C.; Gref, R. Cyclodextrin and polysaccharide-based nanogels: Entrapment of two hydrophobic molecules, benzophenone and tamoxifen. Biomacromolecules 2009, 10, 547-554.

164. Park, W.; Park, S.-J.; Na, K. Potential of self-organizing nanogel with acetylated chondroitin sulfate as an anti-cancer drug carrier. Colloids Surf. B Biointerfaces 2010, 79, 501-508.

165. Kumbar, S.; Kulkarni, A.; Aminabhavi, T. Crosslinked chitosan microspheres for encapsulation of diclofenac sodium: Effect of crosslinking agent. J. Microencapsul. 2002, 19, 173-180.

166. Wang, H.; Xu, Y.; Zhou, X. Docetaxel-loaded chitosan microspheres as a lung targeted drug delivery system: In vitro and in vivo evaluation. Int. J. Mol. Sci. 2014, 15, 3519-3532.

167. Agnihotri, S.A.; Aminabhavi, T.M. Controlled release of clozapine through chitosan microparticles prepared by a novel method. J. Control. Release 2004, 96, 245-259.

168. Kumbar, S.G.; Aminabhavi, T.M. Synthesis and characterization of modified chitosan microspheres: Effect of the grafting ratio on the controlled release of nifedipine through microspheres. J. Appl. Polym. Sci. 2003, 89, 2940-2949.

169. Park, K.M.; Bae, J.W.; Joung, Y.K.; Shin, J.W.; Park, K.D. Nanoaggregate of thermosensitive chitosan-Pluronic for sustained release of hydrophobic drug. Colloids Surf. B Biointerfaces 2008, $63,1-6$.

170. Manaspon, C.; Viravaidya-Pasuwat, K.; Pimpha, N. Preparation of folate-conjugated pluronic F127/chitosan core-shell nanoparticles encapsulating doxorubicin for breast cancer treatment. J. Nanomater. 2012, 2012, doi:10.1155/2012/593878.

171. Seo, S.; Lee, C.-S.; Jung, Y.-S.; Na, K. Thermo-sensitivity and triggered drug release of polysaccharide nanogels derived from pullulan-g-poly (1-lactide) copolymers. Carbohydr. Polym. 2012, 87, 1105-1111.

172. Jeong, Y.-I.; Na, H.-S.; Oh, J.-S.; Choi, K.-C.; Song, C.-E.; Lee, H.-C. Adriamycin release from self-assembling nanospheres of poly (DL-lactide-co-glycolide)-grafted pullulan. Int. J. Pharm. 2006, 322, 154-160.

173. Guo, Y.; Wang, X.; Shu, X.; Shen, Z.; Sun, R.-C. Self-assembly and paclitaxel loading capacity of cellulose-graft-poly (lactide) nanomicelles. J. Agric. Food Chem. 2012, 60, 3900-3908.

174. Jeong, Y.-I.; Kim, D.H.; Chung, C.-W.; Yoo, J.-J.; Choi, K.H.; Kim, C.H.; Ha, S.H.; Kang, D.H. Doxorubicin-incorporated polymeric micelles composed of dextran- $b$-poly (DL-lactide-co-glycolide) copolymer. Int. J. Nanomed. 2011, 6, 1415-1427.

175. Bang, J.-Y.; Song, C.-E.; Kim, C.; Park, W.-D.; Cho, K.-R.; Kim, P.-I.; Lee, S.-R.; Chung, W.-T.; Choi, K.-C. Cytotoxicity of amphotericin B-incorporated polymeric micelles composed of poly (DL-lactide-co-glycolide)/dextran graft copolymer. Arch. Pharm. Res. 2008, 31, 1463-1469.

176. Lee, H.; Ahn, C.H.; Park, T.G. Poly [lactic-co-(glycolic acid)]-Grafted Hyaluronic Acid Copolymer Micelle Nanoparticles for Target-Specific Delivery of Doxorubicin. Macromol. Biosci. 2009, 9 , $336-342$. 
177. Li, B.; Wang, Q.; Wang, X.; Wang, C.; Jiang, X. Preparation, drug release and cellular uptake of doxorubicin-loaded dextran-b-poly(e-caprolactone) nanoparticles. Carbohydr. Polym. 2013, 93, $430-437$.

178. Huang, S.-J.; Sun, S.-L.; Feng, T.-H.; Sung, K.-H.; Lui, W.-L.; Wang, L.-F. Folate-mediated chondroitin sulfate-Pluronic ${ }^{\circledR} 127$ nanogels as a drug carrier. Eur. J. Pharm. Sci. 2009, 38, 64-73.

179. Mundargi, R.C.; Shelke, N.B.; Rokhade, A.P.; Patil, S.A.; Aminabhavi, T.M. Formulation and in vitro evaluation of novel starch-based tableted microspheres for controlled release of ampicillin. Carbohydr. Polym. 2008, 71, 42-53.

180. Barbucci, R.; Fini, M.; Giavaresi, G.; Torricelli, P.; Giardino, R.; Lamponi, S.; Leone, G. Hyaluronic acid hydrogel added with ibuprofen-lysine for the local treatment of chondral lesions in the knee: In vitro and in vivo investigations. J. Biomed. Mater. Res. B Appl. Biomater. 2005, 75, 42-48.

181. Cho, E.; Tahir, M.N.; Choi, J.M.; Kim, H.; Yu, J.-H.; Jung, S. Novel magnetic nanoparticles coated by benzene-and $\beta$-cyclodextrin-bearing dextran, and the sorption of polycyclic aromatic hydrocarbon. Carbohydr. Polym. 2015, 133, 221-228.

182. Saravanakumar, G.; Jo, D.-G.; Park, J.H. Polysaccharide-based nanoparticles: A versatile platform for drug delivery and biomedical imaging. Curr. Med. Chem. 2012, 19, 3212-3229.

183. Liu, Z.; Jiao, Y.; Wang, Y.; Zhou, C.; Zhang, Z. Polysaccharides-based nanoparticles as drug delivery systems. Adv. Drug Deliv. Rev. 2008, 60, 1650-1662.

184. Lemarchand, C.; Gref, R.; Couvreur, P. Polysaccharide-decorated nanoparticles. Eur. J. Pharm. Biopharm. 2004, 58, 327-341.

185. Varde, N.K.; Pack, D.W. Microspheres for controlled release drug delivery. Expert Opin. Biol. Ther. 2004, 4, 35-51.

186. Baimark, Y.; Srisuwan, Y. Preparation of polysaccharide-based microspheres by a water-in-oil emulsion solvent diffusion method for drug carriers. Int. J. Polym. Sci. 2013, 2013, 761870.

187. Xu, J.; Li, S.; Tostado, C.; Lan, W.; Luo, G. Preparation of monodispersed chitosan microspheres and in situ encapsulation of BSA in a co-axial microfluidic device. Biomed. Microdevices 2009, 11, 243-249.

188. He, P.; Davis, S.S.; Illum, L. Chitosan microspheres prepared by spray drying. Int. J. Pharm. 1999, 187, 53-65.

189. Li, B.-Z.; Wang, L.-J.; Li, D.; Bhandari, B.; Li, S.-J.; Lan, Y.; Chen, X.D.; Mao, Z.-H. Fabrication of starch-based microparticles by an emulsification-crosslinking method. J. Food Eng. 2009, 92, 250-254.

190. Mellors, R.; Benzeval, I.; Eisenthal, R.; Hubble, J. Preparation of self-assembled microspheres and their potential for drug delivery. Pharm. Dev. Technol. 2010, 15, 105-111.

191. Davis, S.; Illum, L. Sustained release chitosan microspheres prepared by novel spray drying methods. J. Microencapsul. 1999, 16, 343-355.

192. Rinaudo, M. Main properties and current applications of some polysaccharides as biomaterials. Polym. Int. 2008, 57, 397-430.

193. Wood, K.C.; Chuang, H.F.; Batten, R.D.; Lynn, D.M.; Hammond, P.T. Controlling interlayer diffusion to achieve sustained, multiagent delivery from layer-by-layer thin films. Proc. Natl. Acad. Sci. USA 2006, 103, 10207-10212. 
194. He, W.; Du, Q.; Cao, D.-Y.; Xiang, B.; Fan, L.-F. In vitro and in vivo studies of pectin/ethylcellulosefilm-coated pellets of 5-fluorouracil for colonic targeting. J. Pharm. Pharmacol. 2008, 60, 35-44.

195. Macleod, G.S.; Collett, J.H.; Fell, J.T. The potential use of mixed films of pectin, chitosan and HPMC for bimodal drug release. J. Control. Release 1999, 58, 303-310.

196. Dhanikula, A.B.; Panchagnula, R. Development and characterization of biodegradable chitosan films for local delivery of paclitaxel. AAPS J. 2004, 6, 88-99.

197. Coviello, T.; Matricardi, P.; Marianecci, C.; Alhaique, F. Polysaccharide hydrogels for modified release formulations. J. Control. Release 2007, 119, 5-24.

198. Eiselt, P.; Yeh, J.; Latvala, R.K.; Shea, L.D.; Mooney, D.J. Porous carriers for biomedical applications based on alginate hydrogels. Biomaterials 2000, 21, 1921-1927.

199. Ashley, G.W.; Henise, J.; Reid, R.; Santi, D.V. Hydrogel drug delivery system with predictable and tunable drug release and degradation rates. Proc. Natl. Acad. Sci. USA 2013, 110, 2318-2323.

200. Vandamme, T.F.; Lenourry, A.; Charrueau, C.; Chaumeil, J. The use of polysaccharides to target drugs to the colon. Carbohydr. Polym. 2002, 48, 219-231.

(C) 2015 by the authors; licensee MDPI, Basel, Switzerland. This article is an open access article distributed under the terms and conditions of the Creative Commons Attribution license (http://creativecommons.org/licenses/by/4.0/). 